\title{
Are Chinese social scientists concerned about climate change? A bibliometric analysis and literature review
}

\author{
Fanglei Zhong ${ }^{1,2} \cdot$ Wenru Cheng $^{1} \cdot$ Aijun Guo $^{1} \cdot$ Xiaoyu Song $^{3} \cdot$ Qingping Cheng $^{4} \cdot$ Asmat Ullah $^{5,6,7} \cdot$ Yuan Song $^{8}$
}

Received: 8 April 2021 / Accepted: 4 December 2021 / Published online: 15 January 2022

(c) The Author(s), under exclusive licence to Springer-Verlag GmbH Germany, part of Springer Nature 2021

\begin{abstract}
China has been the world's largest emitter of carbon dioxide since 2006. To achieve the goal of carbon neutrality by 2060 , social scientists must become involved in China's deep decarbonization process. However, Chinese social scientists have given little attention to climate change in their bibliometric research. Based on the Chinese Social Sciences Citation Index journal catalog of the four essential social sciences, namely, management, economics, politics, and sociology, we used the China National Knowledge Infrastructure database to quantify the extent to which Chinese social scientists are concerned about climate change. The results showed that from 1978 to 2020, 1179 articles on climate change were published in management, economics, politics, and sociology journals, which represented only $26.8 \%$ of the 4397 articles published on pollution in the same journals. Politics journals published the most articles (38.76\%), while sociology journals published the fewest (2.37\%). Thus, Chinese social scientists rarely considered climate change, mainly because this topic remains controversial in some fields and because of the influence of international politics in addition to the promotion and incentive mechanisms for researchers. We analyzed the keywords and evolution of climate change research in the four social sciences and our results show that social scientists should give greater emphasis to climate change in their research.
\end{abstract}

Keywords Climate change $\cdot$ Global warming $\cdot$ Chinese journals $\cdot$ Social sciences $\cdot$ Sustainable development $\cdot$ Bibliometrics

Responsible Editor: Baojing Gu

Aijun Guo

Fanglei Zhong

zfl@muc.edu.cn

Wenru Cheng

chengwr19@1zu.edu.cn

Xiaoyu Song

songxy@1las.ac.cn

Qingping Cheng

qpchengtyli@foxmail.com

Asmat Ullah

asmat.ait@gmail.com

Yuan Song

13993123009@139.com

1 School of Economics, Lanzhou University, Lanzhou 730000, China
2 School of Economics, Minzu University of China, Beijing 100081, China

3 Northwest Institute of Eco-Environment and Resources, Chinese Academy of Sciences, Lanzhou 730000, China

4 School of Geography and Ecotourism, Southwest Forestry University, Kunming 650224, Yunnan, China

5 The Joint Graduate School of Energy and Environment (JGSEE), King Mongkut's University of Technology Thonburi, 126 Prachauthit Road, Bangkok 10140, Thailand

6 Center of Excellence On Energy Technology and Environment, PERDO, Bangkok, Thailand

7 US. Pakistan Center for Advanced Studies in Water, Mehran University of Engineering and Technology, Jamshoro, Sindh 76062, Pakistan

8 Gansu Meteorological Information and Technical Equipment Support Center, Lanzhou 730020, China 


\section{Introduction}

Human activities are the main cause of climate change (IPCC 2013). The beginning of the COVID-19 pandemic in December 2019 was another reminder of the importance of harmony between humans and nature in addition to the looming challenge posed by climate change. The International Energy Agency (IEA) estimates that global energy-related carbon emissions must peak no later than 2020 and then fall by $>70 \%$ over the next 35 years if society is to have a reasonable chance $(>66 \%)$ of avoiding dangerous climate change, even if the global population grows and affluence increases during this period (Benjamin et al. 2018). Deep decarbonization requires considerable changes in the global society; therefore, the related policies must become the focus not only of natural scientists but also of social scientists. The United Nations (UN) Intergovernmental Panel on Climate Change (IPCC) has gathered scientists from many fields along with policy-makers and economists to identify and discuss climate change-related factors and their likely impacts, and design practical mitigation strategies (Michael and Zhang 2018). At the Climate Adaptation Summit 2021, UN Secretary-General Antonio Guterres stated that support for climate adaptation action was a moral imperative from a socioeconomic perspective. However, studies indicated that the four essential social sciences, that is, management, economics, politics, and sociology, are currently insufficiently concerned with climate change as demonstrated by the relatively few social science studies focused on climate change (Amanda 2008). With the exception of the rare social science studies that directly address climate change-related topics, there has been little interdisciplinary work, even on topics such as energy needs, where climate change is directly related to socioeconomic disciplines (Stephan and Hannes 2015). This absence from the social sciences literature is clearly not conducive to the proposed goal of the deep decarbonization of society.

In 2006, China overtook the USA as the world's largest emitter of carbon dioxide. By 2018, China's carbon dioxide emissions had reached 10.065 billion tons, accounting for $30.37 \%$ of the total global carbon dioxide emissions. The 2019 Global Carbon Emissions Report released by the IEA (2020) stated that in 2019, China continued to lead the world in terms of carbon dioxide emissions, although they had only risen by a moderate amount. Hence, China's impact on climate change is immense. At the 75th Session of the UN General Assembly on September 22, 2020, President Xi pledged that China would increase its contribution toward mitigating the effects of climate change and adopt more effective policies and measures to promote a green recovery of the world economy after the COVID-19 pandemic. President Xi also highlighted China's efforts to reach a peak in terms of its carbon dioxide emissions by 2030 and outlined efforts aimed at achieving carbon neutrality by 2060 (Xi 2020). The type of development strategy that China adopts will not only have a significant influence on global political and economic patterns, but will also have a significant impact on global actions in dealing with climate change (Wei et al. 2014). To achieve the stated goals, it is necessary to make significant changes to China's socioeconomic development (Zhu et al. 2020), which requires social scientists' involvement.

Over the last decade, the number of articles published in high-quality Chinese journals has exceeded 60,500,000. The number of publications increases annually, which has had a significant impact on Chinese social scientists. As a result, the importance of publishing articles in Chinese is now increasingly emphasized throughout the Chinese academic community, both by management and by the scholars themselves. More importantly, following the historical path dependence on the research scope of problems, academic thinking, and language expression, Chinese social scientists are more inclined than natural scientists to publish in Chinese journals. Chinese social scientists also place greater value on the influence of important Chinese journals. For example, in an article titled "Research on the classification of Chinese journals by university scientific research management department," Liu (2007) observed that both Chinese articles included in the Chinese Social Sciences Citation Index (CSSCI) and English articles included in the Science Citation Index could be considered comprehensive or authoritative. Therefore, a systematic review of Chinese journal articles is necessary to study the extent to which Chinese social science scholars are concerned about climate change. This will not only help to show the world the concerns of Chinese social science scholars regarding climate change, but also facilitate the detailed presentation of their research content, themes, and methods, as well as their outlook regarding future research. Presenting the results of such a review in English journals will also increase international scholars' understanding of the Chinese social science scholars' perspectives and promote their knowledge exchange.

Social scientists can influence the perceptions of decisionmakers, policy-makers, and the general public in relation to climate change and responsible consumption and production. Therefore, it is imperative to analyze the involvement of social scientists in climate change-related research and the publication of articles in this area. Moreover, this type of research has a significant influence on the advocacy for and sensitization of issues associated with climate change. The results of this study provide a preliminary understanding of the extent to which articles published by social scientists have been instrumental in addressing climate change. To the best of our knowledge, no previous studies on this issue have been conducted. Although some social scientists are 
actively engaged in climate change research, most of their work has been published in natural science journals. However, from a mainstream perspective, publication in social science journals can better illustrate the degree to which scholars in all academic disciplines are involved in the study of climate change.

This study focuses on analyzing how many climate change-related articles have been published in Chinese social science journals. A total of 154 journals in the four essential social sciences, that is, management, economics, politics and sociology, included in the CSSCI by the China Social Science Research and Evaluation Center at Nanjing University, were selected for the retrieval of data related to climate change. The data were taken from the China National Knowledge Infrastructure (CNKI) database for quantitative research, which is conducive to exploring the developmental process of social science research on climate change, increasing the attention paid by social scientists to climate change, and formulating more scientific policies and mechanisms to deal with climate change. These efforts thereby more effectively mitigate the impacts of climate change.

\section{Methodology and data}

\section{Methodology}

Bibliometric methods allow us to extract the most relevant topics and articles from large databases, identify the most important information contained in those articles, and analyze past and present research trends to identify the most active research frontiers. CiteSpace, an information visualization software tool based on citation analysis theory using the Java programming language, is a popular bibliometric analysis tool widely used to analyze research hotspots and trends in various fields. By drawing a visual map and establishing the associations among the nodes to analyze the cooccurrence and co-citation relationships among the research objects, the research development history can be shown on a knowledge map of a citation network. The literature of citation nodes and the research frontiers characterized by co-citation clustering can be automatically identified on the knowledge graph. This demonstrates the readability of the knowledge graph (Chen et al. 2015).

\section{Data sources}

The data used in this study were obtained from the CNKI database, which includes journals, master's and doctoral theses, conference papers, and newspapers. It is currently the largest academic literature database in China, with more than 50,000 updates daily. Developed by Nanjing University, the CSSCI database (2019-2020) lists 154 journals in the fields of management, economics, politics, and sociology. Its design is mainly based on bibliometric theory using a combination of quantitative and qualitative evaluation methods to select source journals with strong scholarship and editorial specifications from more than 2,700 Chinese academic journals in the humanities and social sciences in China. The database can be used to search for articles and citations in the Chinese social sciences and is considered a landmark project in relation to the evaluation of the humanities and social sciences fields in China. The Chinese Ministry of Education has used CSSCI data as an important indicator for the evaluation of national academic institutions, award evaluation, project establishment, evaluation of famous and excellent journals, and talent training models. In this paper, mainly select "retrieval of journals" in the advanced retrieval function of the CNKI database, with search terms, including "global warming" or "climate change," set to keyword, title, or abstract (Table 1).
Table 1 Sample data retrieval conditions

\begin{tabular}{ll}
\hline Retrieval condition category & Retrieval condition setting \\
\hline Time span & January 1, 1978-August 31, 2020 \\
Database & CNKI \\
Journal source & CSSCI \\
Retrieval strategy 1 & Title= "climate change" or "global warming" \\
& or abstract="climate change" or "global \\
& warming" or keywords = "climate change" or \\
& "global warming" (a total of 1179 valid stud- \\
ies were retrieved from the literature) \\
Retrieval strategy 2 & Title= "pollution" and not including "cli- \\
& mate change" and "global warming" or \\
abstract = "pollution" and not including \\
"climate change" and "global warming" and \\
not including "climate change" and "global \\
warming" (a total of 4397 valid references \\
were retrieved) \\
\hline
\end{tabular}


The results showed that as of September 1, 2020, 1203 climate change-related articles had been published. Conference reports, news promotions, book promotions, and book reviews were then excluded, which reduced the total by 26 . Thus, a sample of 1177 articles on climate change or global warming was obtained by exporting and transcoding the target literature based on the CiteSpace reference format. In addition, for baseline comparative analysis, the previous search terms were replaced with "pollution" and articles including the terms "climate change" or "global warming" were excluded. The results showed that as of September 1, 2020, 4439 articles had been published. Conference reports, news promotions, book promotions, and book reviews were excluded, which reduced the total by 42 . Thus, 4397 articles on pollution were available for analysis.

\section{Results}

\section{$\mathrm{CSSCl}$ source journals on climate change concerns in the four essential social sciences}

\section{Distribution of posting times}

The annual number of articles published is an important measure of the strength and development of trends in climate change research. Figure 1 shows that during the period 1982-2020, 70 economics journals were listed in the CSSCI, which is the largest number of journals among the four essential social sciences; thus, it is necessary to examine these journals separately. A total of 467 articles related to climate change or global warming were identified in economics journals, including 10 that were either conference reports, news promotions, book promotions, or book reviews. These 10 articles were excluded, which left a sample of 457 articles.

The overall trend in relation to articles on climate change published in economics journals is consistent with that in the other three essential social sciences. As shown in Fig. 1, three distinct periods are seen based on the number of publications. During the period 1982-2006, relatively few articles on climate change were published in the four essential social sciences, with an annual maximum of 11 articles. During the same period, even fewer articles on climate change were published in economics journals, with no more than 10 articles published annually. No articles related to climate change or global warming were published in economics journals in the periods 1984-1988, 1990-1992, and 2003-2004. The period 2007-2014 saw a gradual but significant increase in the number of articles on climate change or global warming, with the largest number of articles on these topics published in 2010 and 2011. In 2010, 162 articles were published in the four essential social sciences. After 2011, the number of articles published on climate change declined sharply before increasing again in 2016. Since 2017, however, the number
Fig. 1 Number of articles on climate change published in economics journals

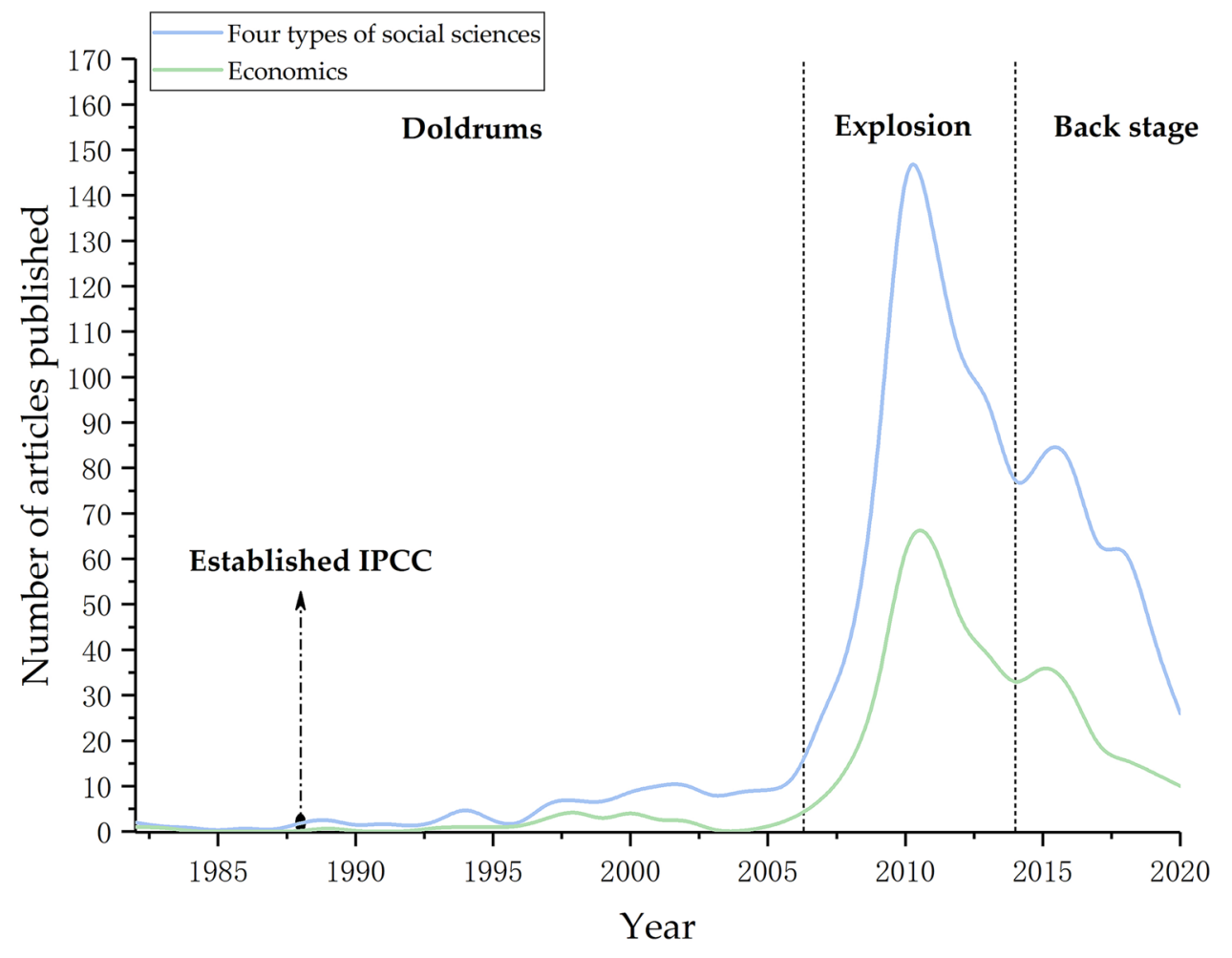


of articles published on climate change or global warming has declined significantly, with no more than 20 articles published in economics journals each year.

\section{Distribution over time for articles published in the four essential social sciences}

Comparing the number of articles published in the four essential social sciences, Fig. 2 shows that the overall trends in the number of articles published on climate change or global warming are similar. In particular, numerous articles have been published in three social sciences: management, economics, and politics. Publications in both economics and politics journals began to increase substantially after 2006, while publications in management science journals increased substantially after 2008 . The number of publications in all four social sciences peaked in 2010 and then declined.

Figure 2 shows some key events since the turn of the twenty-first century. In 2007, the Nobel Peace Prize was jointly awarded to former US Vice President Al Gore and the IPCC in recognition of their accumulation and dissemination of knowledge about human-induced climate change, which laid the foundation for the measures that were needed in response. This provided the impetus for Chinese and international scholars in numerous fields to start studying climate change, which resulted in a substantial increase in the number of articles published. The 2009 World Climate Conference held from December 7 to 18 in Copenhagen, Denmark, saw fierce debate among developing and developed countries on carbon emissions, development rights, and human rights. This debate was scrutinized by many governments, nongovernmental organizations, scholars, the media, and the public, and may have led to the number of published articles on climate change peaking in 2010. In November 2015, the UN held a climate change conference in Paris and adopted the Paris Agreement, which once again resulted in extensive discussion among the international community and may have led to the increase in the number of articles published in 2015 and 2016.

\section{Comparative analysis of publications on similar topics.}

To illustrate the relative degrees of attention to different topics in the same types of journals, it is useful to select a similar but different research topic for comparison. In this study, we used articles in social science journals related to pollution as our comparison benchmark. The advantage of using pollution as a comparison term is that there is a correlation between climate change and pollution (which is associated with emissions in the popular consciousness) to some extent, but the two terms are applied differently in the literature. Thus, we replaced the search terms "climate change" and "global warming" with the term "pollution" to remove articles about climate change or global warming from the search results. The resulting data provided a baseline for comparison.
Fig. 2 Number of articles on climate change published in journals related to the four essential social sciences

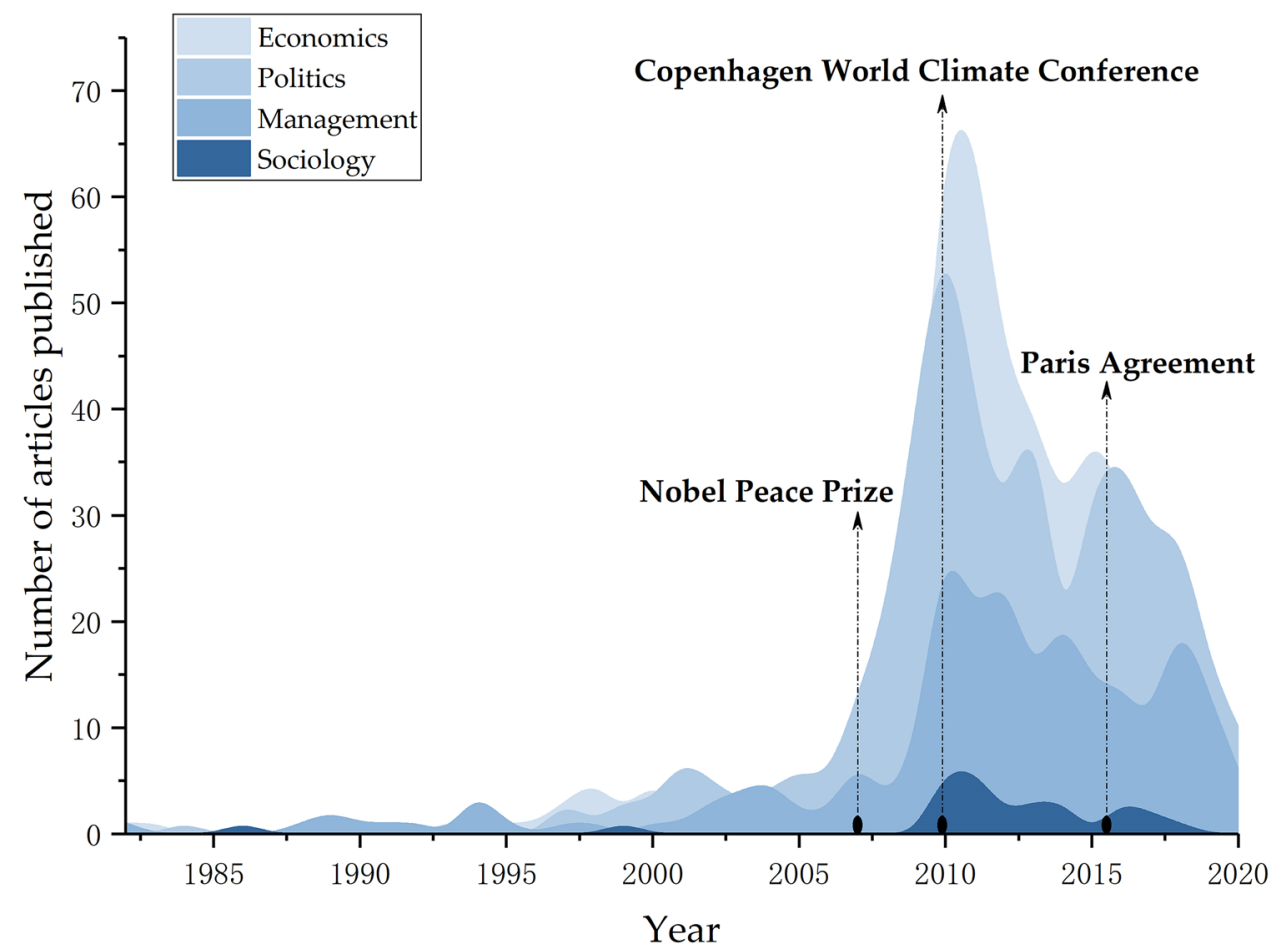


As of September 1, 2020, 4397 articles on pollution had been published, compared with only 1179 articles on climate change or global warming (representing $26.81 \%$ of the number of articles on pollution). Significantly fewer articles on climate change or global warming than on pollution were published in both the journals listed in the CSSCI catalog and across all journal categories. Figure 3 shows the annual number of articles published on climate change or global warming and pollution in all journal categories, with 577,950 articles on pollution and only 159,367 articles on climate change or global warming (representing $27.57 \%$ of the pollution publications).

In the CNKI database, 2777 pollution-related articles published by economics journals were retrieved. This total included 88 articles related to climate change or global warming, which were excluded, as were a further 14 articles that were either conference reports, news promotions, book promotions, or book reviews. Thus, data were collected for 2675 articles. Only 457 articles on climate change or global warming, or just $17.08 \%$ of the number of articles on pollution, were published in these journals. Until 2020, the number of articles on climate change or global warming was less than the number of articles on pollution in every year (Fig. 4).

\section{Comparative analysis of the number of articles in the four essential social sciences}

Figure 5 shows the number of articles on climate change or global warming published in journals related to the

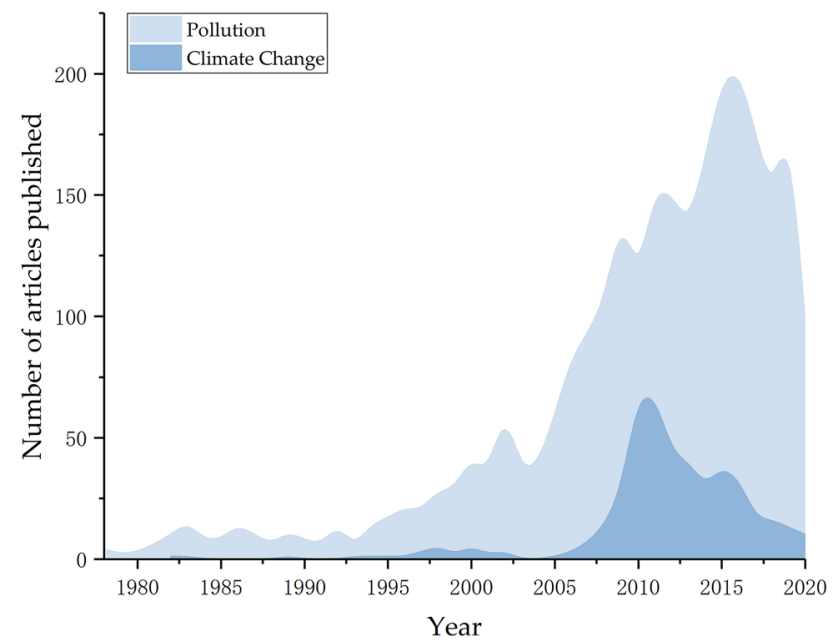

Fig. 4 Number of articles published on climate change or global warming and pollution in economics journals

four essential social sciences. Twenty-eight articles were published in 11 sociology journals, or $2.37 \%$ of the total number of articles published. Two hundred thirty-seven articles were published in 36 management science journals (20.11\%). Economics and politics journals published 457 articles each (38.76\% of the total), but there were 70 economics journals and only 37 politics journals; thus, articles on climate change or global warming accounted for a larger share of articles published in politics journals. This indicates
Fig. 3 Number of articles published on climate change or global warming and pollution in all journal categories

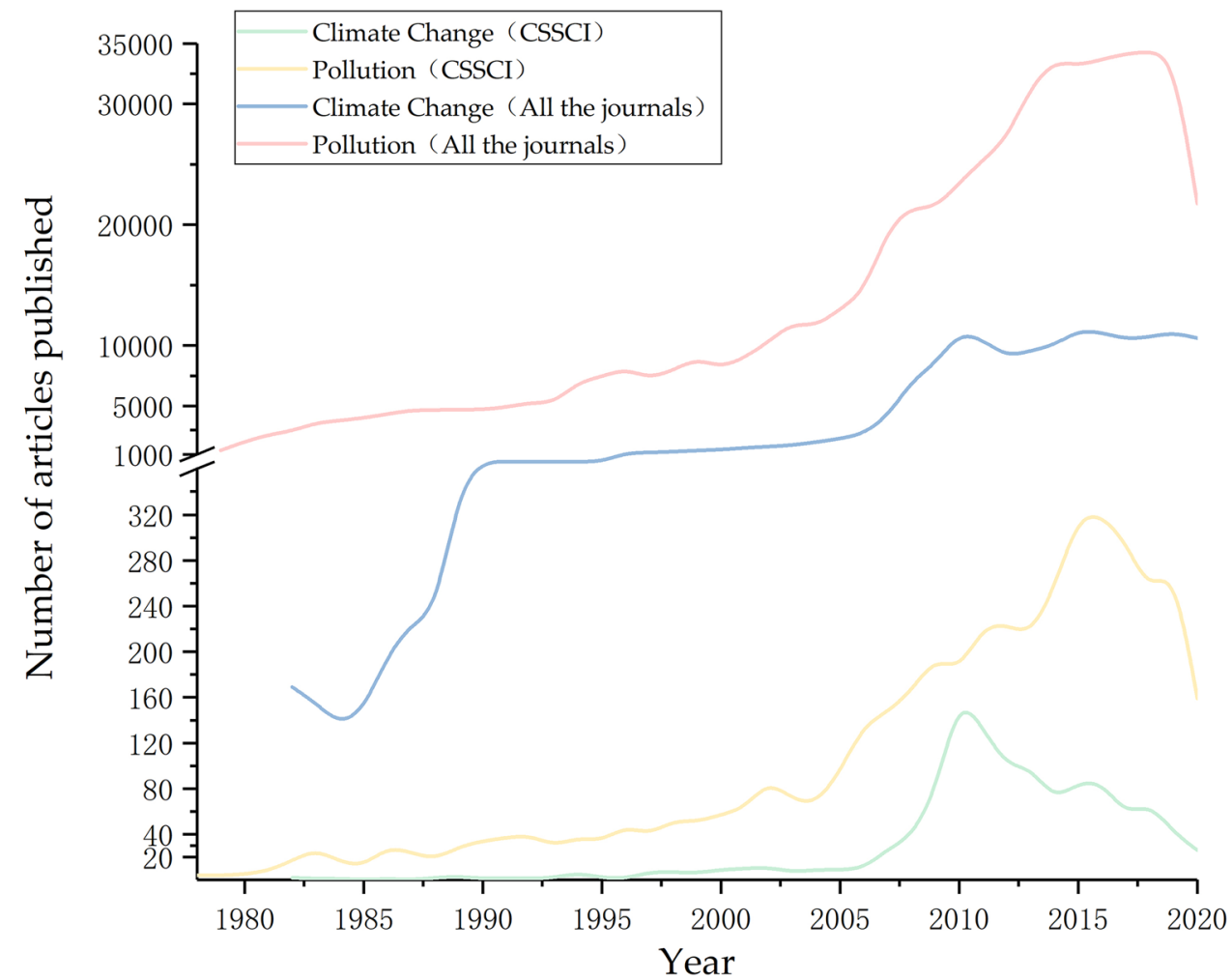


Management

Economics

Politics

Sociology

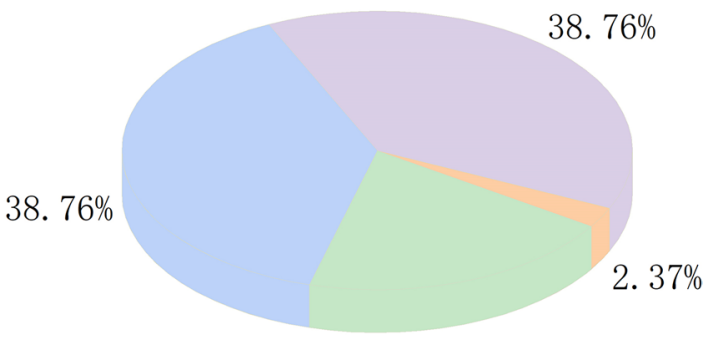

$20.11 \%$

Fig. 5 Number of articles on climate change or global warming in journals related to the four essential social sciences

that of the four essential social sciences, politics showed the highest level of concern regarding climate change or global warming.

Table 2 shows that the most articles in CSSCI source journals were published in politics journals, which comprise six of the top 10 journals in terms of articles published. Of the 10 institutions with the greatest number of articles published, many are focused on international relations. The top 10 authors in terms of the number of articles published are shown in Table 3, most of whom are focused on international relations, urban development, and environmental research. Table 3 also shows the large number of articles and the high level of attention devoted to climate change in the field of international relations.
Thus, both the annual and overall total number of articles published on pollution exceeded those of articles published on climate change or global warming. Therefore, it is clear that the four essential social sciences, especially sociology, do not sufficiently emphasize climate change or global warming.

\section{Factors influencing social scientists' concerns about climate change}

\section{Lag in the transfer of climate change issues from the natural sciences to the social sciences}

Climate change was first placed on the agenda as an issue of international concern in 1979 at the first World Climate Conference in Geneva, Switzerland. In 1982, journals in the four essential social sciences began to publish articles on climate change. In 1988, the UN established the IPCC to assess the state of climate change and its impacts. Following the establishment of the IPCC and the publication of the UN Framework Convention on Climate Change (UNFCCC), climate change or global warming has received more attention than in previous years (Fig. 1). Because the development of climate change is a process from natural science to social science, it is difficult to quantitatively analyze the impact of climate change on humanity. Figure 3 shows that the number of journal articles on climate change or global warming began to rise in 2007, reaching a peak in 2010, which is consistent with the trend in publication numbers in journals related to the four essential social sciences shown in Fig. 2. Since 2007 , the number of articles has fallen slightly, but remained above 10,000 annually since 2014 . This finding confirms that

Table 2 The top 10 CSSCI source journals and institutions in terms of the number of articles published in the four essential social sciences

\begin{tabular}{|c|c|c|c|c|}
\hline $\begin{array}{l}\text { Top } 10 \text { journals publishing the most climate } \\
\text { change articles }\end{array}$ & Social science & $\begin{array}{l}\text { Number of } \\
\text { published } \\
\text { articles }\end{array}$ & $\begin{array}{l}\text { Top } 10 \text { institutions publishing the most climate } \\
\text { change articles }\end{array}$ & $\begin{array}{l}\text { Number of } \\
\text { published } \\
\text { articles }\end{array}$ \\
\hline World Economics and Politics & Politics & 61 & $\begin{array}{l}\text { School of International Relations and Public } \\
\text { Affairs, Fudan University }\end{array}$ & 11 \\
\hline China Soft Science & Management & 50 & School of International Studies, Peking University & 11 \\
\hline Pacific Journal & Politics & 47 & Shanghai Institutes for International Studies & 10 \\
\hline International Forum Journal & Politics & 46 & $\begin{array}{l}\text { Institute of World Economics and Politics Chinese } \\
\text { Academy of Social Sciences }\end{array}$ & 9 \\
\hline World Outlook & Politics & 43 & $\begin{array}{l}\text { Institute of American Studies, Chinese Academy } \\
\text { of Social Sciences }\end{array}$ & 8 \\
\hline Contemporary International Relations & Politics & 33 & $\begin{array}{l}\text { School of International Studies, Renmin Univer- } \\
\text { sity of China }\end{array}$ & 8 \\
\hline Forum on Science and Technology in China & Management & 33 & $\begin{array}{l}\text { Institute of Urban and Environmental Studies } \\
\text { Chinese Academy of Social Sciences }\end{array}$ & 5 \\
\hline Inquiry into Economic Issues & Economics & 27 & China Institute of International Studies & 5 \\
\hline Chinese Journal of European Studies & Politics & 26 & $\begin{array}{l}\text { Guanghua School of Management, Peking Uni- } \\
\text { versity }\end{array}$ & 5 \\
\hline Journal of Agrotechnical Economics & Economics & 25 & $\begin{array}{l}\text { Institute of International Relations, China Foreign } \\
\text { Affairs University }\end{array}$ & 4 \\
\hline
\end{tabular}


Table 3 The top 10 authors in terms of the number of articles published in the CSSCI source journals in the four essential social sciences and their organizational affiliations

\begin{tabular}{llc}
\hline $\begin{array}{l}\text { Top } 10 \text { authors with the most pub- } \\
\text { lished climate change articles }\end{array}$ & Author affiliations & $\begin{array}{c}\text { Number of } \\
\text { published } \\
\text { articles }\end{array}$ \\
\hline Hongyuan Yu & Shanghai Institutes for International Studies & 24 \\
Guiyang Zhuang & Institute of Urban and Environmental Studies, Chinese Academy of Social Sciences & 17 \\
Jiankun He & Institute of Low-Carbon Economy, Tsinghua University & 11 \\
Jiahua Pan & Institute of Urban and Environmental Studies, Chinese Academy of Social Sciences & 11 \\
Ying Chen & Institute of Urban and Environmental Studies, Chinese Academy of Social Sciences & 11 \\
Haibin Zhang & School of International Studies, Peking University & 10 \\
Wei Li & International Business School, Beijing International Studies University & 7 \\
Huiming Li & School of Political Science and Law University of Jinan & 5 \\
Jianying Ma & School of International Relations and Public Affairs, Fudan University & 5 \\
Chenyang Liu & APEC Study Center of Nankai University & 5 \\
\hline
\end{tabular}

climate change has received attention in a wider range of scientific disciplines, including the social sciences, which are beginning to place more emphasis on the subject of climate change and global warming than in previous years.

\section{Influence of political factors on global issues.}

Climate change is a global issue; thus, international conventions are not only developed from a scientific perspective, but also involve political factors such as national interest negotiations. Of the four essential social sciences, politics has published the largest number of articles related to climate change or global warming, which indicates that politics places greater emphasis on these concerns than the other essential social sciences. For example, at the 15th Meeting of the Parties to the 2009 UNFCCC held in Copenhagen, negotiators from 192 countries discussed the successor program to the global emissions-reduction agreement from 2012 to 2020 after the first phase of the Kyoto Protocol expired. With global warming of $2{ }^{\circ} \mathrm{C}$ and the total amount of carbon emissions known, a reasonable quota allocation for each country must be determined. These discussions focused on the right of each country to development, which led to a wide range of discussions among social scientists, culminating in numerous published articles. For example, when former US President George W. Bush took office in 2000, he was skeptical regarding climate change and strongly opposed to the Kyoto Protocol. In 2017, then US President Donald Trump announced that the USA was withdrawing from the 2015 Paris Agreement. These events have had a great impact on climate change research in the social sciences.

\section{Journal publication and the academic promotion mechanism.}

The CSSCI includes 154 journals related to the four essential social sciences, but the top 10 journals in terms of their composite impact factors had only published 54 articles on climate change as of September 1, 2020, accounting for only $4.58 \%$ of the total of 1179 published articles. This indicates that the higher quality journals have fewer articles on climate change and have more stringent criteria for publication. For example, Economic Research Journal is the top-ranked journal based on its composite impact factor of 8.436 and the number of citations. However, since its founding in 1955 , the journal has published 8372 articles (as of September 1, $2020)$, but only $10(0.12 \%)$ of these articles were on climate change, the first of which was published in January 2010. Unfamiliarity with a new field of research increases the difficulty for reviewers to assess the quality of articles submitted for publication. This could delay the emergence of issues such as climate change in top journals. In addition, authors tend to submit articles based on the scope of research previously published in top journals, which may make their articles more acceptable to these journals. Moreover, authors' research topics generally follow their own professional knowledge, which allows for publication of many articles. However, producing results in an interdisciplinary research field is generally very difficult. These interdisciplinary studies are also very time-consuming with many uncertainties. In addition, these researchers must consider the long-term development of their careers, such as whether the direction and subject of their articles will be limited by academic promotion mechanisms and journal ranking.

\section{Analysis of the evolution of research topics and content}

\section{Keyword co-occurrence analysis.}

A research hotspot reflects the emphasis and direction of a field of research, which is of great significance for in-depth understanding and analysis of the research content in that 
field. Keywords summarize the essential content of an article; thus, keyword co-occurrence analysis can be used to determine the research focus in a given field. For the present study, the time frame was set as 1982-2020, which was divided into individual years (Fig. 6). Each node represents an article. The larger the node, the higher the keyword frequency and the greater its relevance to the topic. Similarly, the color of a node represents the amount of time that has elapsed. The brighter the color, the more recently the article was published.

The co-occurrence maps of the keywords in climate change or global warming articles published in journals related to the four essential social sciences showed that the most frequently co-occurring keywords were "climate change" and "low-carbon economy." Not only were there numerous "carbon"-related words, but there were also words representing countries, organizations, policies, and agreements. This confirms that climate change not only affects individual countries but also has a global impact.
The results of a separate analysis of articles on climate change published solely in economics journals are shown in Fig. 7. The most frequently occurring keywords are still "climate change" and "low-carbon economy," while numerous other keywords are related to carbon and focus on the issue of carbon emissions from an economic perspective. For example, carbon tax, carbon finance, low-carbon agriculture, carbon tariff, and other carbon emissions-reduction measures are generally based on the principle that carbon emissions are regarded as a kind of exchangeable commodity, which can be better distributed by economic mechanisms to move closer to the Pareto optimal state.

\section{Keyword cluster analysis.}

Keyword cluster analysis is based on keyword co-occurrence analysis. The co-occurrence network is simplified to a relatively small number of clusters using cluster statistics. In the present study, the keyword cluster analysis

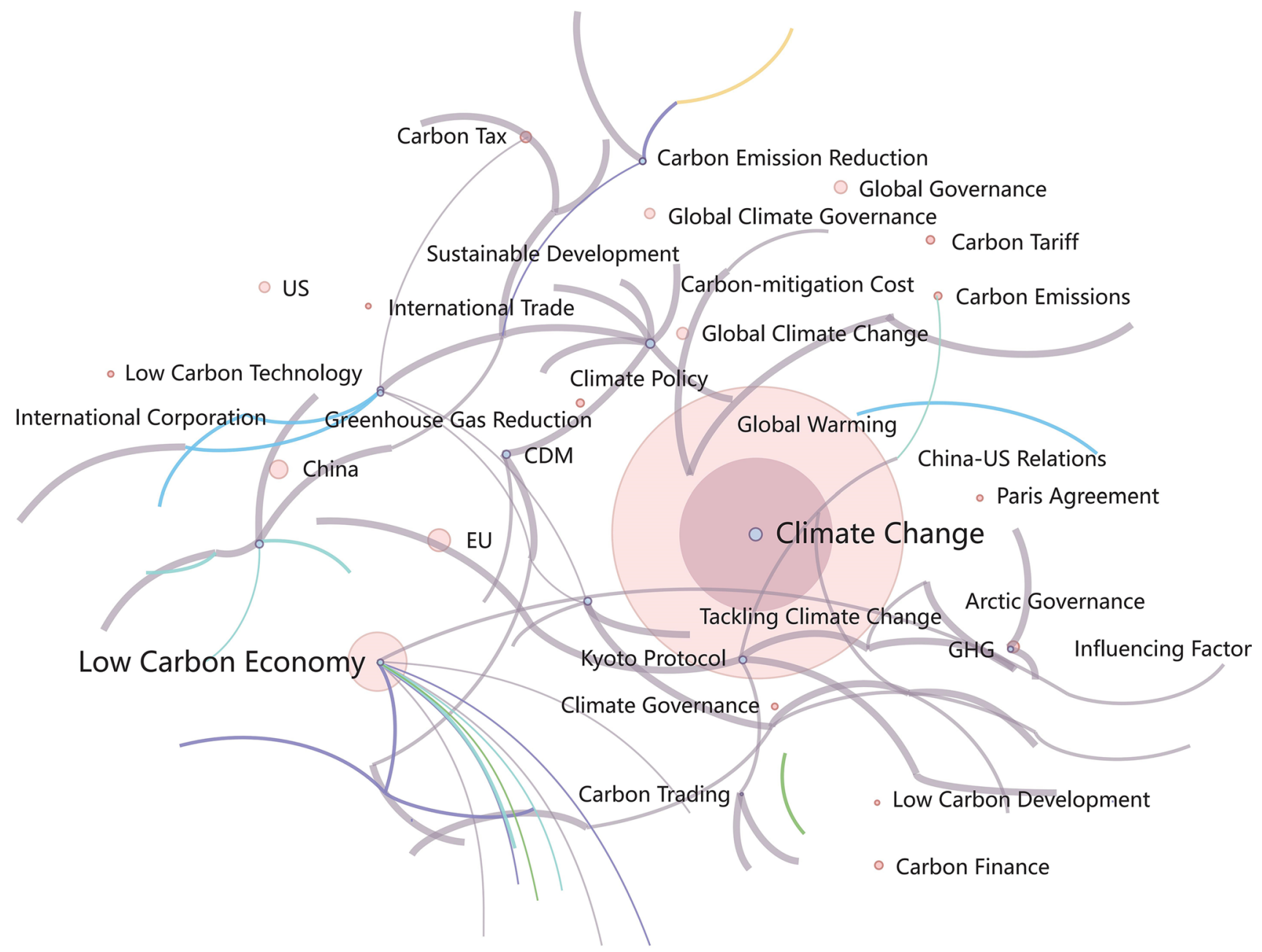

Fig. 6 Co-occurrence map of keywords in articles on climate change in journals related to the four essential social sciences 
Fig. 7 Co-occurrence map of keywords in articles on climate change published in economics journals

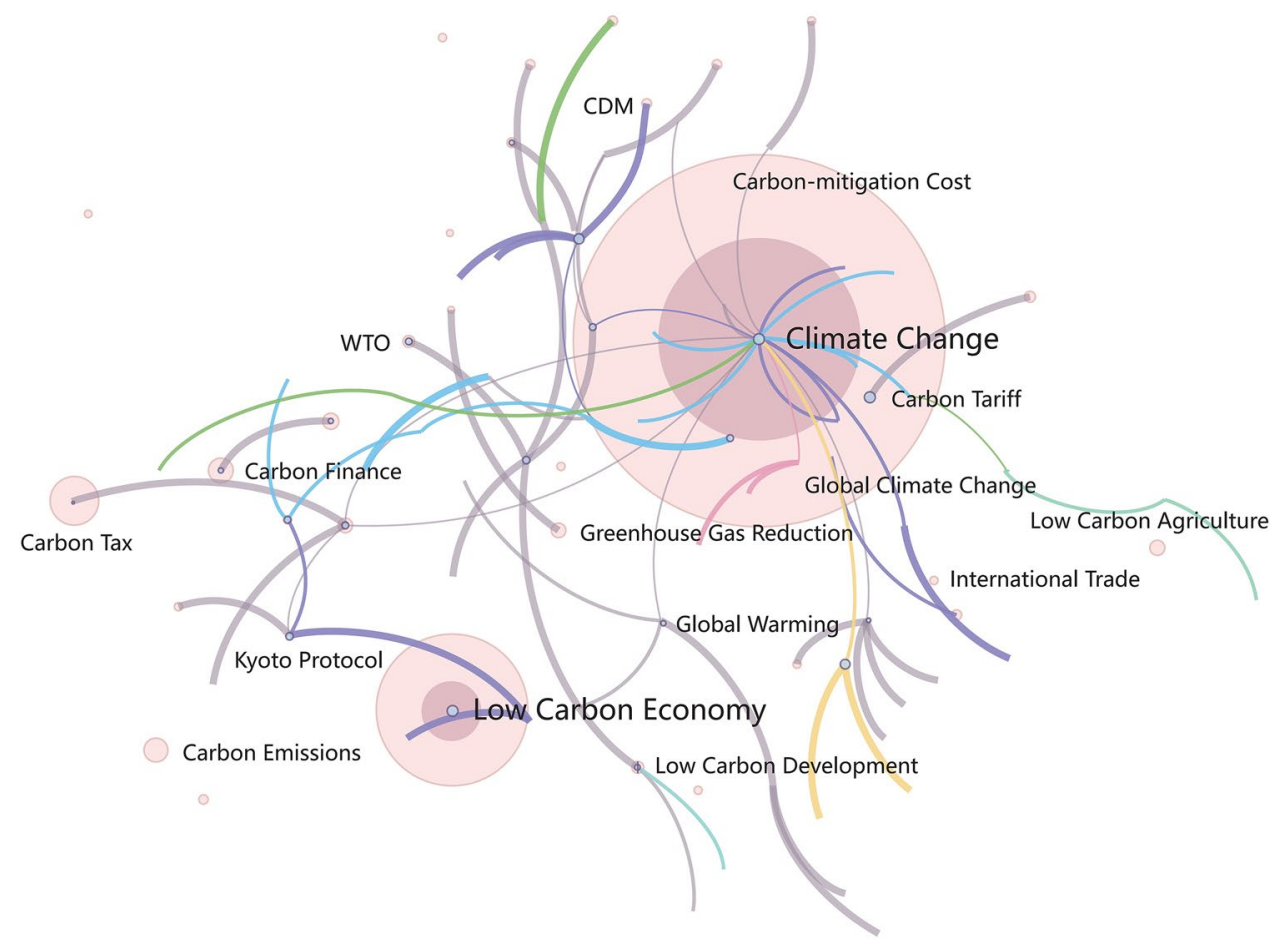

used CiteSpace software to generate a keyword cluster map (see Fig. 8). These clusters reflect the current hot issues in relation to climate change research in the four essential social sciences. In this study, we selected the first nine cluster labels.

Based on the keyword cluster map, the logarithmic likelihood ratio is obtained in Cluster Explorer using the clustering label extraction algorithm, and the clustering table of the keyword co-occurrence network is presented (see Table 4).

The cluster labels are arranged based on cluster size and the first five label words are selected from each cluster label. The tag words reflect efforts by the UN and various governments to tackle the impact of climate change, including improving economic development models and entering into contracts to collectively mitigate the impact of global warming. The actions of some major countries, such as China and the USA, have had a significant influence, and some specific events, such as the announcement by the Trump Administration in 2017 that the USA would withdraw from the Paris Agreement, have led to extensive discussions among scholars both in China and internationally.

Figure 9 shows the current hot issues in relation to climate change research in the field of economics. The first 10 cluster labels are selected and the research contents of each cluster are cross-linked.

Similarly, based on the cluster graph in Fig. 9, Table 5 extracts the label words contained in each cluster of keywords from articles on climate change in economics, which reflects the focus set of economics.

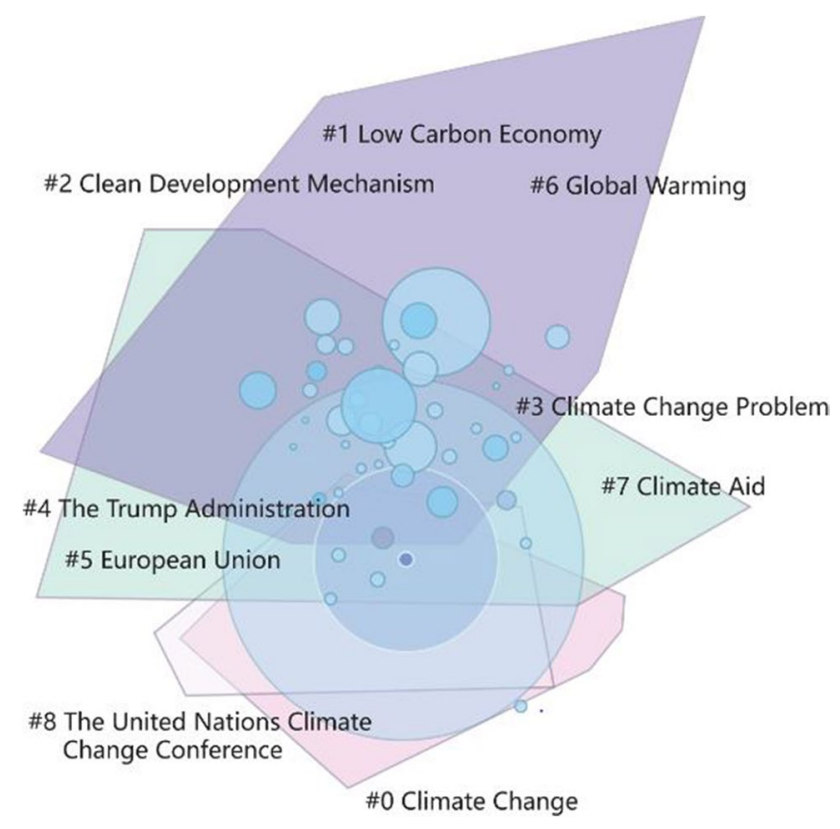

Fig. 8 Clustering of keywords in articles on climate change published in the four essential social sciences

\section{Keyword highlighting.}

Emergence words are keywords that are quoted more frequently over a given period and reflect research trends during that period. In the present study, we used CiteSpace to analyze trends in the development of climate change research in the four essential social sciences (see Fig. 10). 
Table 4 Clustering of keywords in articles on climate change published in journals related to the four essential social sciences

\begin{tabular}{lll}
\hline $\begin{array}{l}\text { Clustering } \\
\text { number }\end{array}$ & Cluster size & Label words (top 5) \\
\hline 0 & 101 & Climate change; climatic data; altitude; climatological information; introduction of domestication \\
1 & 74 & Low-carbon economy; financial innovation; negative externalities; environmental capital; carbon emissions trading \\
2 & 62 & $\begin{array}{c}\text { Climate change; clean development mechanism; international emissions trading; joint performance of the contract; } \\
\text { carbon dioxide problem }\end{array}$ \\
3 & 48 & Kyoto Protocol; climate change; international climate regime; China's negotiating position; climate warming \\
4 & 47 & Trump administration; Sino-United States relations; One Belt and One Road; presidential leadership; win-win \\
5 & 45 & Climate change; Obama administration; new energy policy; group of countries; economic rice farming culture \\
6 & 42 & Global warming; agricultural trade; computable general equilibrium model; Global Trade Analysis Project; climate \\
& & change \\
7 & 39 & Climate change; climate aid; climate finance; fund for South-South cooperation; climate cooperation \\
8 & 17 & National security; Copenhagen conference; economic recovery; Obama administration; climate change policy \\
\hline
\end{tabular}

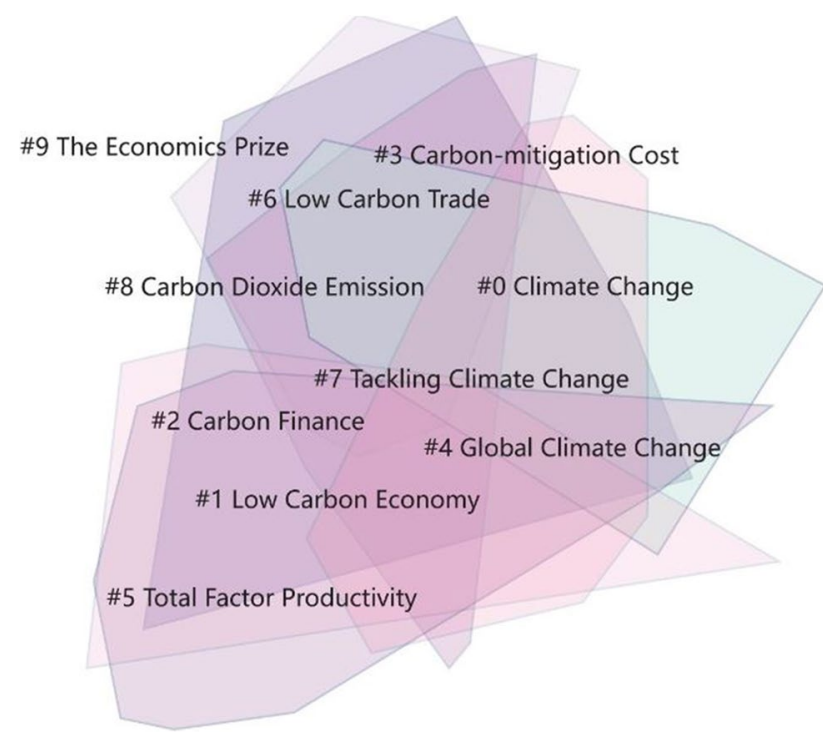

Fig. 9 Cluster map of keywords in articles on climate change published in economics journals

The keywords are sorted by the date when they initially gained prominence. Global warming has been a topic of concern for a long time. Other keywords were more affected by specific events, such as the Paris Agreement, which came into force in November 2016, and the keyword "Paris Agreement" has been emerging since then, with a pop-up intensity of 6.7792 . The November 2019 announcement by the Trump Administration that the USA was commencing the formal process of withdrawing from the Paris Agreement also increased the intensity of the emergence of the keyword "Paris Agreement." Fig. 10 shows that the keyword "lowcarbon economy" has the highest pop-up intensity of 19.13, which means that this keyword received the most attention during the period 2009-2012. The 2009 Copenhagen Climate Change Conference presented the possibility of a lowcarbon economy to the people of the world and since then, the consensus on the need to develop a low-carbon economy has been growing. Former President Hu Jintao promised at the 2009 meeting that China would further integrate climate change into its socioeconomic development plans and continue to take strong measures, including vigorously developing a green, low-carbon, circular economy. In the following year, Yang (2010a, b) stated that a low-carbon economy is the inevitable future form of the global economy and pointed out that a new Industrial Revolution with a low-carbon economy at its core had arrived. The value of the label variable of "low-carbon economy" showed great change in a short time; thus, it became an inflection point with a high intensity of emergence.

Figure 11 presents information on the emergence of keywords in articles on climate change in economics journals. "Global warming" remains the earliest keyword, while "low-carbon economy" remains the keyword with the highest emergent intensity, indicating that it was also the keyword that experienced the greatest change between 2010 and 2011 in the economics discipline. In August 2010, China's National Development and Reform Commission launched a pilot project promoting low-carbon industrial development in eight cities in five provinces. In the same year, low-carbon elements could be seen everywhere at the Shanghai World Expo, which demonstrated the concept of a low-carbon environment. Because of the high degree of correlation between food production and climate change, "food production" has been appearing as a keyword in economics journals since about 2018, which also reflects the corresponding increase in demand for food in China. For example, in China's 13th Five-Year Plan, binding targets for grain production have been proposed to ensure China's food security.

\section{Evolution of research topics over time.}

A keyword timing map can be used to show how the main content of a research subject changes over time and can 
Table 5 Clustering of keywords in articles on climate change published in economics journals

\begin{tabular}{|c|c|c|}
\hline $\begin{array}{l}\text { Clus- } \\
\text { tering } \\
\text { number }\end{array}$ & Cluster size & Label words (top 5) \\
\hline 0 & 59 & Climate change; space economics; William; Nordhaus; rice model \\
\hline 1 & 35 & $\begin{array}{l}\text { Low-carbon economy; transition to a low-carbon economy; low-carbon industrialization; low-carbon technology } \\
\text { innovation; development path }\end{array}$ \\
\hline 2 & 24 & Climate change; financial innovation; environmental finance; policy recommendations; COVID-19 \\
\hline 3 & 20 & $\begin{array}{l}\text { Emission reduction potential; mitigation of climate change; scientific controversy; political interpretation; economic } \\
\text { assessment }\end{array}$ \\
\hline 4 & 20 & $\begin{array}{l}\text { Global climate change; strategy selection; climate change negotiations; reducing greenhouse gas emissions; world } \\
\text { economics and politics }\end{array}$ \\
\hline 5 & 20 & Total factor productivity; Malmquist index; low-carbon economy; influential factors; industrialization process \\
\hline 6 & 20 & Trade in agricultural products; trade pattern of agricultural products; El Nino; tackling climate change; biodiesel \\
\hline 7 & 19 & $\begin{array}{l}\text { Tackling climate change; forest carbon sink; poverty alleviation through forest carbon sink; poverty alleviation effect; } \\
\text { World Trade Organization rules }\end{array}$ \\
\hline 8 & 19 & $\begin{array}{l}\text { Industrialization and urbanization; climate change; the principle of common but differentiated responsibilities; envi- } \\
\text { ronmental Kuznets curve hypothesis; UNFCCC }\end{array}$ \\
\hline 9 & 13 & Climate change; economics prize; loss function; macroeconomic analysis; technological change \\
\hline
\end{tabular}

\section{Top 13 Keywords with the Strongest Citation Bursts}

Keywords Year Strength Begin End

Global Warming $1982 \quad 7.0787 \quad 1991 \quad 2008$

Kyoto Protocol $\quad 1982 \quad 11.7597 \quad 19992009$

$\begin{array}{lllll}\text { Greenhouse gas } & 1982 & 4.2705 & 1999 & 2009\end{array}$

Climate change $\quad 1982 \quad 4.2598 \quad 2003 \quad 2007$

problem

Carbon Finance 1982

Low Carbon Economy 1982

Arctic Governance 1982

Global Governance 1982

Low Carbon

Development 1982

European Union 1982

Climate Governance 1982

Paris Agreement 1982

Global Climate

Governance

1982

4.120320092012

19.1320092012

$3.6292 \quad 2012 \quad 2017$

3.657620122016

$4.2672 \quad 2012 \quad 2014$

4.936320122015

4.903120152018

6.779220162020

8.047120172020
$1982-2020$

Fig. 10 Keyword emergence maps for articles on climate change published in journals related to the four essential social sciences

also reflect research trends to some extent. Based on the co-occurrence analysis of keywords, the time series maps of the keywords in the climate change research published in the four essential social sciences were generated based on the time segment (see Fig. 12).

Based on the co-occurrence analysis of keywords in articles on climate change published in journals related to the four essential social sciences, time sequence maps were generated from 1990, sliced into year-long segments. "Climate change" is the first keyword that scholars in these four social sciences focused on, a trend that continued until 2020. The appearance of the terms "EU" and "Sino-United States relations" in the time sequence maps shows that international relations also have a significant impact on climate change. 


\section{Top 13 Keywords with the Strongest Citation Bursts}

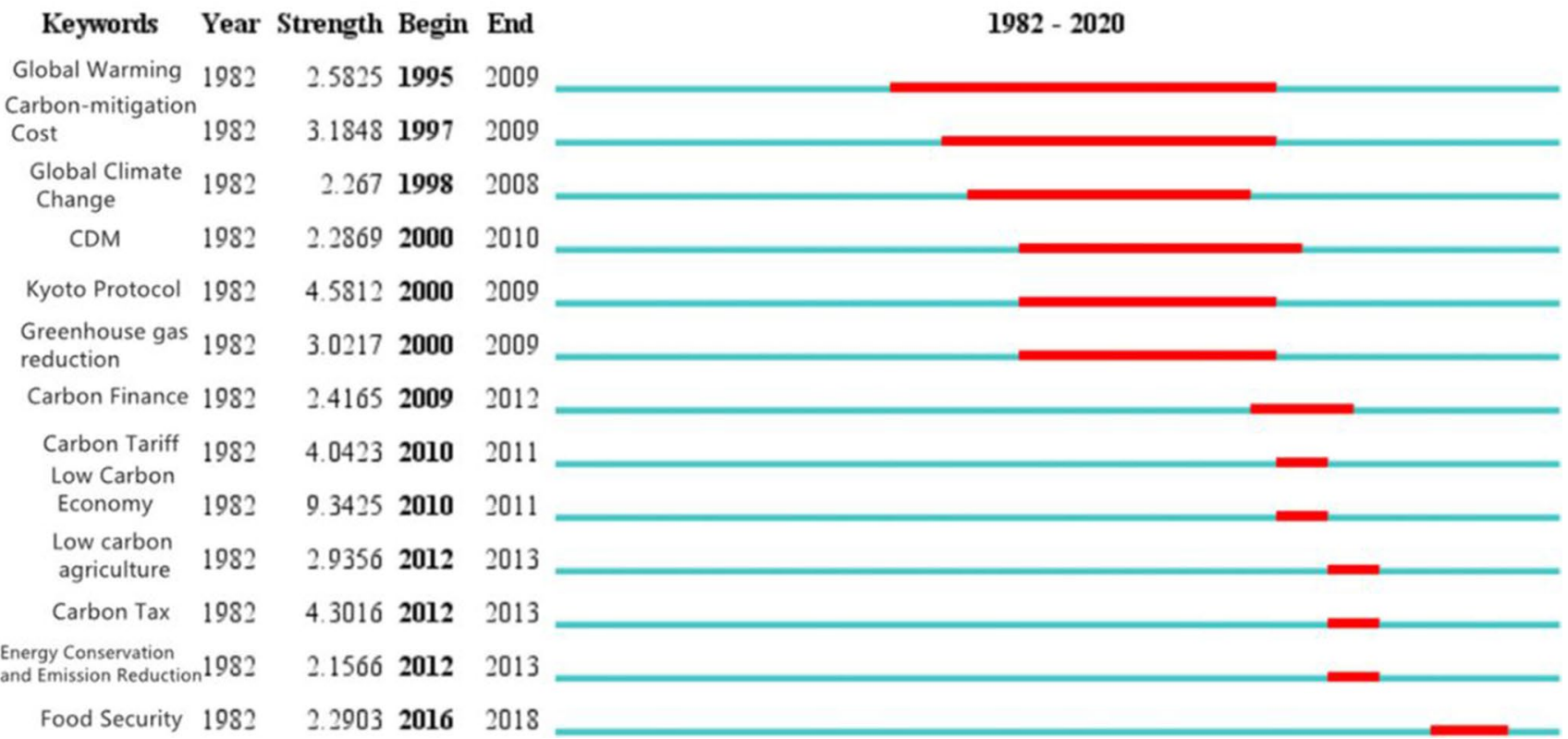

Fig. 11 Keyword pop-up intensities for articles on climate change published in economics journals

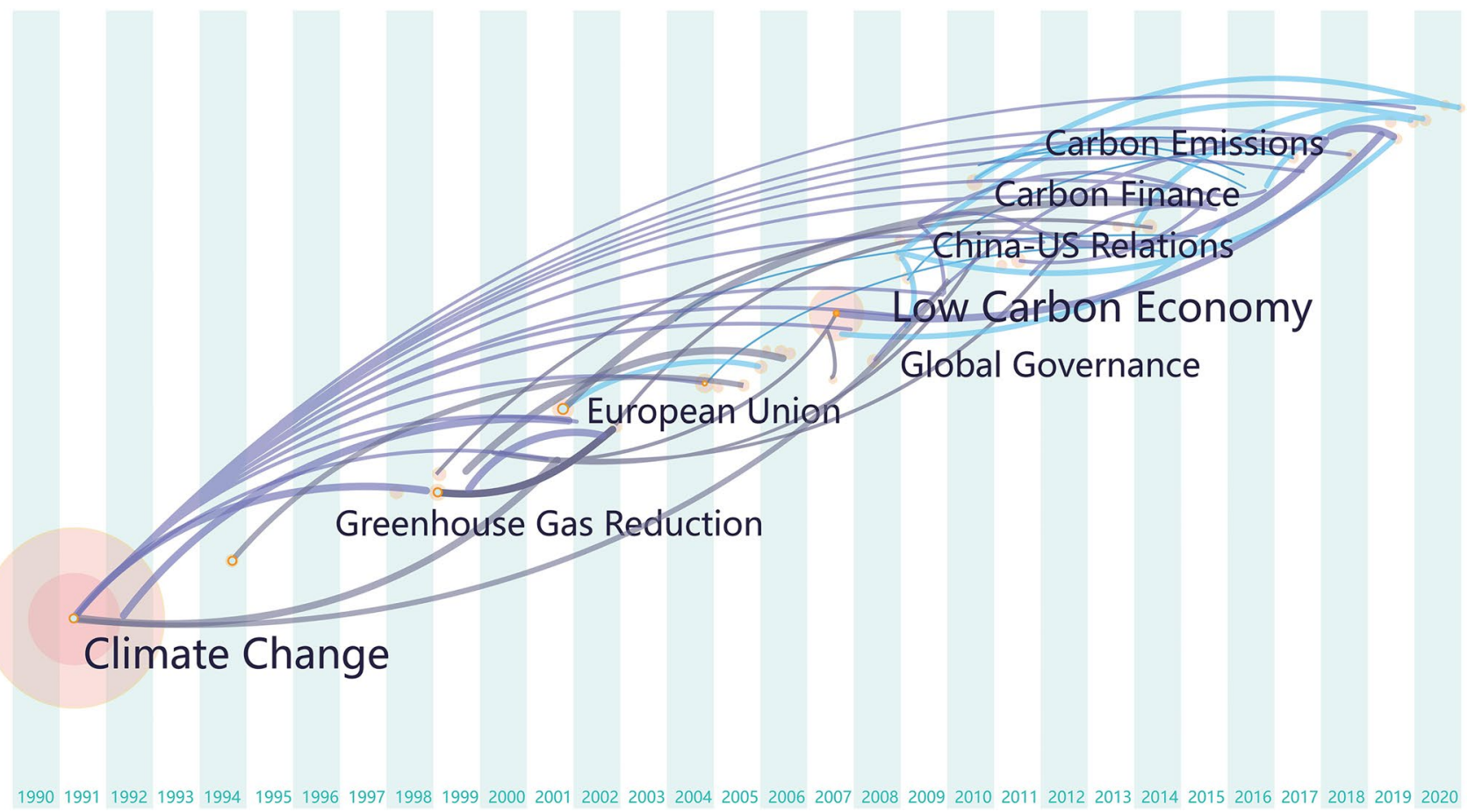

Fig. 12 Keyword pop-up intensities for articles on climate change published in journals related to the four essential social sciences

Figure 13 shows the time series of keywords for articles on climate change published in economics journals. Climate change is the first keyword emphasized by economists and that trend continued until 2020. Since the beginning of the focus on a low-carbon economy in 2007, the aim has been to reduce carbon emissions, both from the industrial perspective and the development of related financial derivatives. 


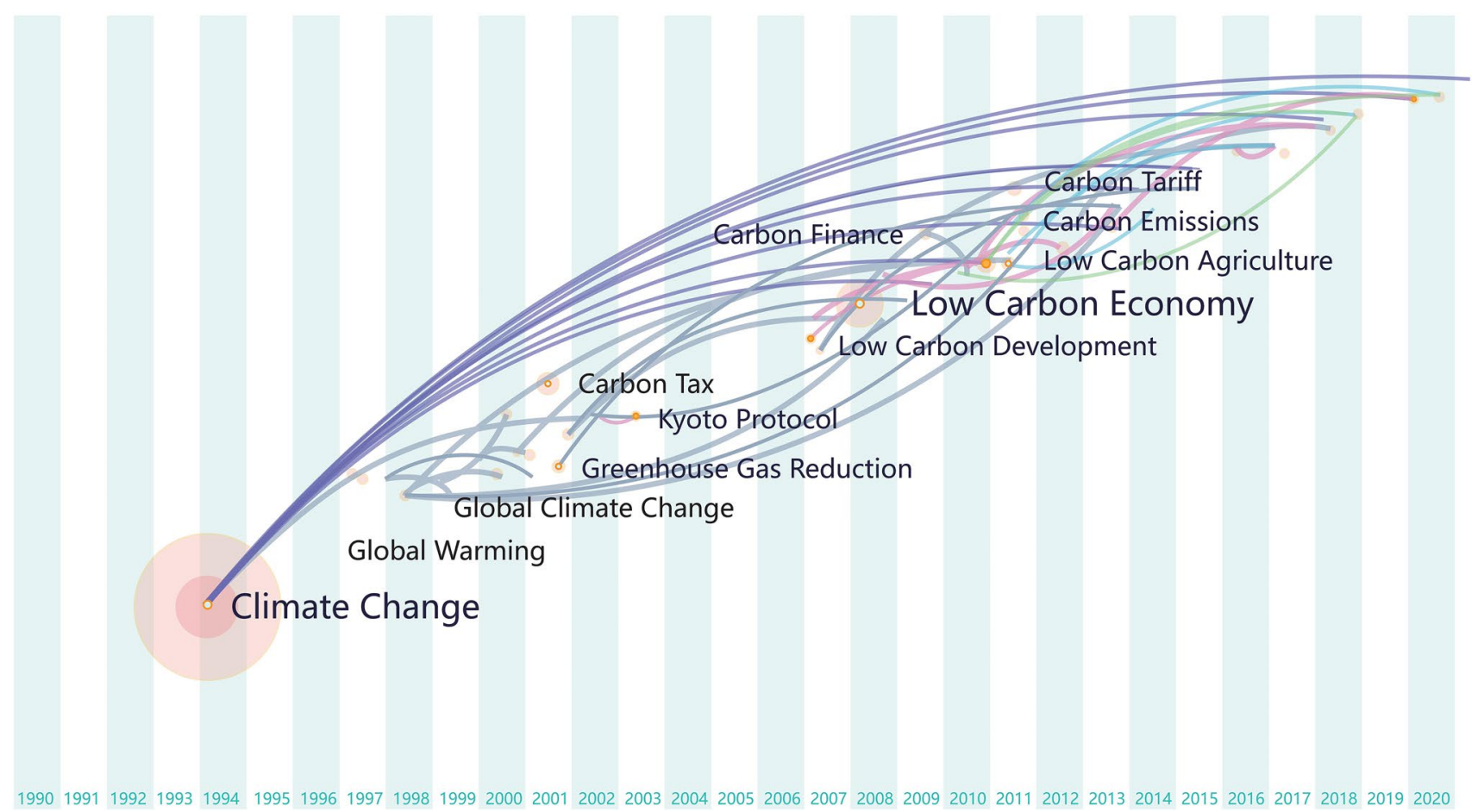

Fig. 13 Time series of keywords for articles on climate change published in economics journals

\section{Review of climate change research in Chinese social science journals}

Our analysis of the articles on climate change or global warming published in CSSCI source journals in the four essential social sciences provides an understanding of the characteristics of articles on climate change or global warming. We then analyzed the differences in focus and future directions among the four social sciences in terms of their published research on climate change or global warming.

\section{Review of climate change research in economics journals and prospects.}

The CSSCI source journals include a large number of economics journals. Our analysis of the attention given in economics journals to climate change or global warming showed that these publications were mainly focused on the macro perspective and various issues, such as the impact of climate change on economic growth and the effects of policies aimed at dealing with climate change. The study of climate change within economics can be summarized as consisting of four directions: economic analysis, economic models, financial instruments, and policy implications.

\section{Economic analysis.}

The impact of climate change on the economy is examined using economic analysis models or environmental analysis tools, which form the basis of developing targeted strategies to mitigate the effects of climate change. Taking winter wheat as an example, Lin and Lu (2019) explored the impact of climate change on the total factor productivity of winter wheat. Their results showed that a nonlinear relationship existed between climate-related factors and the total factor productivity of winter wheat. They observed that high temperatures would significantly reduce the total factor productivity of winter wheat. In addition, the long-term impact of climate change on winter wheat would be greater than the current impact; therefore, measures should be taken to deal with climate change as soon as possible in an attempt to minimize these adverse effects. Luo et al. (2018) examined the impact of climate change on economic activities from three perspectives - economic growth, agricultural productivity, and the labor market-and summarized the policy tools needed for adaptation to and mitigation of climate change. $\mathrm{Hu}$ et al. (2015) examined the main forms of carbon barriers in relation to international trade in the context of climate change, analyzed the possible adverse effects of these barriers on China's future international trade, and suggested coping strategies. Chen and Lin (2019) identified a causal link between the energy environment and key variables of 
concern in the economics of climate change based on microdata and a newly developed causal identification tool in the field of econometrics.

\section{Economic models.}

To determine how China should deal with climate change, discussion of China's economic growth model and development stages is necessary, especially those with Chinese characteristics, which differ from the development experiences of other countries. Table 5 shows that CSSCI economics journals mainly focus on future development models featuring climate change mitigation represented by a low-carbon economy. This model emphasizes that, based on the concept of sustainable development, the consumption of high-carbon energy, such as that obtained from coal and oil, and the emission of greenhouse gases shall be reduced as far as possible through technological innovation, institutional innovation, industrial transformation, and the development of new energy sources to achieve a win-win outcome involving both socioeconomic development and ecological and environmental protection. Ye (2013) analyzed the challenges faced by China's urban transformation, both at home and internationally, and proposed some suggestions for the selection of a pathway for China's urban transformation to a low-carbon economy from the perspectives of industrial development, foreign trade, energy structure, and technology to provide reference points for addressing climate change and low-carbon economic development. A study published in Economic Research Journal that discussed the driving factors behind the growth of $\mathrm{CO}_{2}$ emissions as a result of China's economic development, emissions-reduction policy, developing a lowcarbon economy, climate change, and implementing a strategy of sustainable development has great theoretical and practical significance (Wang et al. 2010). Of the 457 articles retrieved, the most cited was "Low-carbon economy and the transformation of China's economic development model," which was also an exploration of China's transition to a lowcarbon economic development model. That article analyzed both the factors restricting and the potential advantages of a transformation to a low-carbon economy, and suggested some strategies aimed at facilitating this transformation (Jin and Liu 2009).

\section{Financial instruments.}

These articles include research on financial and property rights, among other economic measures. It should be emphasized that economic measures, such as defined property rights, enable trade behavior among economic actors to effectively solve related externalities such as carbon emissions. Carbon emission rights can be clarified by carbon emission subjects to reduce trading costs. The invisible hand of the market can ensure an efficient solution to emissionsrelated problems. Carbon emission rights can also be seen as a commodity. Financial derivatives can be developed and innovated, which enables carbon emission rights to be allocated optimally, thereby achieving the goal of reducing carbon emissions and mitigating climate change. For example, Cao and Yao (2014) analyzed and compared three carbon emission-reduction strategies based on industry credit-quality data from large state-owned commercial banks and proposed policy suggestions from the perspectives of a carbon emissions-reduction mechanism, a climate mitigation strategy, and prudent operation of the banks. Based on the aim of developing a low-carbon economy, Lin (2012) studied the development of the international carbon financial market and the risks involved, and proposed some suggestions on how to develop the domestic carbon financial market based on the experiences of the international carbon financial market.

\section{Policy implications.}

The global nature of climate change means that it must be addressed through international policies and agreements. Therefore, evaluating the impact of national or regional development policies is a hot topic in economic research. Qiao and He (2016) examined the 2015 Paris Agreement and its impact on the global economy using a historical analysis of carbon emissions. They pointed out that the essence of the Paris Agreement is still the inequality of historical cumulative emissions, which is the second layer of exploitation of developing countries, taking advantage of their dependency status and the urgent need to improve the ecological environment. The Paris Agreement was also seen as affecting the international division of labor and the global economy through the adjustment of the international energy structure based on carbon emissions-reduction constraints. Ma et al. (2009) conducted an in-depth study of the businessas-usual (BAU) scenario and relative emissions reductions proposed during the Copenhagen Conference negotiations and performed an in-depth analysis of the concepts underlying the BAU scenario and relative emissions reductions, the results of which will contribute to safeguarding China's socioeconomic development and interests. Xu (2001) provided a commentary on the United States' withdrawal from the Kyoto Protocol, which analyzed the deep-seated reasons for their decision and its effect on both the United States and other countries.

Climate change has clearly had a significant impact on all socioeconomic fields, including strong externalities. Economists have extensively researched how to mitigate and adapt to the impact of climate change. Regardless of whether these studies have been based on economic models or financial instruments, the aim is to reduce the impact of climate change-induced shocks on economic development using 
economic tools and policy recommendations. Although Chinese research on the impact of climate change on the economy has produced numerous important findings, we also found some shortcomings during our literature review. The first was a lack of practicability in terms of the models used. Obviously, economic research should be economically useful, but the complexity of the mechanisms by which climate change affects the economy makes it difficult for models to consider all of the important variables, such as the welfare of future generations. Even if all factors are considered, many questions must be addressed. For example, it is difficult to select an appropriate discount rate and a small discrepancy in the discount rate might result in significant under- or overestimation of the projected costs of climate change mitigation projects. Therefore, while the estimates obtained using these models can serve as a basic reference point, they cannot provide an effective solution to the ongoing problem of climate change. Second, the availability of data is inadequate. Although scholars have paid considerable attention to the economic impact of climate change, the frequency of extreme climate events and their data types are very limited. Therefore, previous empirical studies have mainly used temperature, precipitation, and other weather data, and there has been little research into the impact of extreme climate events. In addition, the policy is less effective. To reduce the impact of climate change, numerous studies have proposed various mitigation and adaptation approaches, but the results of their implementation through a range of policies have been unsatisfactory (Luo 2018). While adaptation policies can reduce the impact of climate change, they are more about strengthening future response programs and preparations, with limited impact on current climate issues. While direct regulation, taxes, subsidies, and pollution rights trading can have an immediate effect, they may add additional costs to the development of a country or industry. In reality, there is a significant amount of "freeriding" (Harry 2014).

In the future, Chinese economists must pay greater attention to climate change and establish a theoretical framework, including energy, the environment, and climate change that reflects Chinese characteristics and culture. Methods to mitigate carbon emissions should be explored while achieving sustainable socioeconomic development, international mechanisms for addressing climate change that provide an opportunity for countries to achieve sustainable development, and the development of theories and analytical methods aimed at supporting the transition from an industrial civilization to an ecological civilization (He et al. 2014a, b). Based on our literature review and analysis, future research on the impact of climate change on the economy should consider the following three directions. First, attention should be paid to the impact of catastrophic climate events on the economy. Weitzman (2011) observed that the probability density function of climate damage is a "thick-tailed distribution" when simulating the influence of extreme weather events. Weitzman (2011) believed that disasters such as hurricanes and floods that exceeded the thresholds of traditional models had a high probability of occurrence, much higher than had previously been expected, and that the resulting economic losses would be immeasurable. To date, relatively few studies have explored the probability of extreme weather events and the resulting economic losses. Second, importance must be given to climate change-related externalities and international cooperation should be promoted. Climate change-related issues have strong externalities and "freeriding" behavior is common. Therefore, even when effective mitigation policies are available, some governments refuse to adopt them. In addition, countries that have introduced carbon pricing are concerned about economic growth and development opportunities shifting to other countries (Deschenes 2010). No effective solutions to these problems currently exist; therefore, an important direction for future research on climate change economics is how to promote international cooperation to implement energy conservation and emissions-reduction policies. Third, there must be more discussion on adaptive behaviors and policies. Policies involving adaptation to climate change have two key characteristics. First, they are obviously private in nature and thus are less affected by "free-rider" behavior than mitigation policies. Second, the potential economic losses caused by climate change are greater for some countries than for others; therefore, these countries will introduce mitigation policies even when there is no sense of international cooperation. Accordingly, some forms of adaptive behavior may be conducive to international cooperation (Seraina and Gunter 2010). Thus, it is important to continue to investigate adaptive behaviors and policies.

\section{Review of climate change research in management journals and prospects.}

The issue of climate change is receiving increasing attention and is no longer a research topic for only the natural sciences. Climate change is raising a number of issues for corporate managers, investors, and other stakeholders in relation to corporate management and investment. Carbon emissions from products and services, regulatory risks related to climate change, product and technology risks, litigation risks, and reputational risks all affect the costs, asset mix, and scope of companies' activities, and shareholders' decisions will increasingly be influenced by the financial consequences of the carbon emissions control regime.

With international and domestic concerns about climate change, companies that voluntarily reduce their carbon emissions are better able to demonstrate their ability to manage the value of their companies, mitigate the concerns 
of relevant stakeholders about their future prospects, and enhance the liquidity of their stocks. Low-carbon management helps to enhance their corporate image and brand value, and conveys the message to the public that "the company is sustainable and worthy of long-term trust," thereby increasing market recognition and raising expectations of the company's values and long-term development prospects. In contrast, companies that do not engage in low-carbon management are easily challenged by the public and environmental organizations. In addition, under the consensus to address climate change, low-carbon management has attracted considerable attention from investors who consider climate change as a result of carbon emissions to be an important strategic issue for companies. Investors convey their concerns about climate change to companies, which prompts them to consider addressing climate change and energy-saving policies as a long-term strategy. This strategy is beneficial for both companies' long-term development and the environment. China continues to increase its autonomous dedication to addressing climate change through the introduction and implementation of a series of policies aimed at limiting carbon emissions. The negative externalities generated by regulating enterprises' emissions-reduction behavior will be translated into increased costs for enterprises and consumers. However, the benefits gained by enterprises that undertake high-carbon operations will be less than the costs of violating the regulations and these companies might even be shut down. In contrast, enterprises undertaking lowcarbon operations and low-carbon management will be supported and subsidized under the state's policies. Following these intensifying government emissions controls, companies taking passive measures will increasingly experience a disadvantageous competitive position. A significant number of enterprises that adopted passive responses to these increasing requirements have already been eliminated from the market.

We analyzed 237 articles on climate change from 36 management journals in CSSCI source journals focusing on the micro level, such as the impact of climate change and mitigation policies and mechanisms on energy use, and hence on the development of various industries. Research on climate change in the management discipline can be summarized as including management transformation for climate change adaptation and mitigation, environmental auditing, and technological innovation.

\section{Management transformation for climate change adaptation and mitigation.}

Setting reasonable and specific carbon reduction targets from the perspective of management using objectives is a key to mitigating the greenhouse effect. In addition, a green transition is an effective means of mitigating the effects of climate change. On the demand side, an interdisciplinary approach to determine solutions and study their mitigation potential could be used to make polluters pay through either taxes or carbon trading schemes as a means of making energy savings and emissions reductions more profitable, thereby encouraging enterprises and households to use more renewable energy and less energy overall to reduce emissions (Lin 2019). Combining different national carbon trading market mechanisms and trading rules, for example, Yang (2010a, b) outlined the present situation regarding the domestic carbon trading market and the construction of an improved carbon trading market in China. Yang (2010a, b) then proposed some suggestions, including the formation of a carbon price discovery mechanism, promoting the development of carbon trading intermediaries, and fostering the consumption demand of carbon trading. Additionally, studies have explored the feasibility of issuing a low-carbon lottery in China, which mainly shows that China can feasibly issue a low-carbon lottery using several factors, such as economics, market potential, technology, and laws. Thus, issuing a low-carbon lottery plays a positive role in raising funds for low-carbon development, developing the low-carbon industry, and mitigating and adapting to climate change (Luo and Liang 2012).

\section{Environmental auditing.}

Improved resource and environmental auditing is helpful in promoting the implementation of a sustainable development strategy. As part of the shift to high-quality economic development, resource and environmental auditing plays an active role in energy development, environmental protection, ecologically friendly construction, and climate change mitigation. Studies have explored the impact of environmental accounting and environmental information disclosure on the cost of capital. For example, He et al.'s (2014a, b) article, "Carbon disclosure, carbon performance, and cost of capital," which examined the impact of corporate carbon information disclosure on carbon performance and the cost of capital, has been cited more than 200 times.

\section{Technological innovation.}

Improving the energy use structure and increasing investment in clean technology research and development (R\&D) are also effective ways to combat climate change. On the supply side, we can promote the energy and technological revolutions by means of taxation and industrial development funds, and support innovative research into new energy, energy-saving, and emissions-reduction technologies. In an effort to perfect the green patent system and improve the green technology patent application and transfer system, $\mathrm{Chu}$ and $\mathrm{Xu}$ (2012) proposed some innovative measures in 
relation to patent granting conditions and the patentee's obligations. Zou et al. (2019) analyzed the main bodies of clean technology innovation in China and found that the R\&D mode of industry-university-research institute has shifted from university-private enterprises to research institutes and state-owned enterprises.

In the current environment of continual adaptation to and mitigation of the effects of climate change, the relationships among enterprises, nature, and various stakeholders will become increasingly entwined. All enterprises are part of both natural and supply chain ecosystems. When those enterprises, nature, and various stakeholders are able to achieve "positive exchanges," they will be able to enhance their value. Low-carbon management is a social responsibility that enterprises must achieve. Managers who pay attention to climate change and their organization's carbon emissions can address in advance the risks that climate change presents to their organization and identify innovative businesses and products. In future research on climate change, it will be worthwhile to examine how to allocate emissions-reduction targets to micro-organizations and individuals from a management perspective. Management scientists should also pay greater attention to the mutual impact of the behaviors of micro-actors and climate change, and explore ways to more effectively motivate micro-actors to reduce their emissions. At the same time, corporate managers and stakeholders should be more proactive regarding emissions-reduction strategies based on their business goals by promoting lowcarbon management strategies among multiple stakeholders, including financial institutions, other enterprises, and governments, and examining issues related to corporate operations and management in the context of a low-carbon economy.

\section{Review of climate change research in political science journals and prospects.}

Climate change is undoubtedly a global political problem with implications for future political approaches because the seemingly simple scientific acknowledgment of climate change has evolved into a complex, long-term political issue. Since the beginning of the twenty-first century, the responses of the USA to the Kyoto Protocol and the Paris Agreement have weakened the authority of the UN regarding the global negotiation process in relation to climate change, which has led to the internalization of external differences in terms of global climate politics. During the climate negotiation process, developing countries have unanimously emphasized that the developed countries should bear the historical responsibility for climate change, while the developing countries, although willing to participate in climate negotiations, have refused to make emissions-reduction commitments equal to or greater than those of the developed countries. The issue of climate change is receiving increasing attention from all countries and regions, and affects the attitudes and positions of governments at all levels when dealing with the challenges of climate change. China's attitude toward climate change has shifted from ignorant but active, to active but passive, to cautious and conservative, and finally to active and pragmatic. China has continually increased its contribution to emissions-reduction efforts. The deep decarbonization practices introduced by China and other emerging powers appear to have changed the geographical patterns of global climate politics.

The above analysis and Fig. 5 show that of the four essential social sciences, politics journals published the most articles on climate change or global warming in the CSSCI source journals. Our analysis of these articles revealed that articles on climate change in management journals were mainly focused on the international level and explored areas of agreement and difference between the UN and governments around the world in response to climate change, in addition to various agreements and conventions between governments and international organizations aimed at dealing with climate change. These articles explored the levels of cooperation and strategic relations between China and other countries and organizations in the context of joint efforts to cope with the impacts of climate change. Research on climate change in political science journals can be summarized as focusing on international convention negotiations and environmental diplomacy.

\section{International convention negotiations.}

On the surface, climate change is an environmental issue, but it is essentially both a political and economic issue (Zhuang and Chen 2001). World Economics and Politics has the highest combined impact factor of political periodicals among the CSSCI periodicals and the most published articles on climate change or global warming. The articles that the journal published were almost exclusively about China's role in global climate governance positioning and strategic choices (Zhuang et al. 2018). The journal has also focused on China's negotiating position during international climate conferences to explore China's development from the perspective of the influence of politics climate conventions. The UNFCCC, the Kyoto Protocol, the Paris Agreement, and other international conventions were all signed following intensive negotiations. There are differences among countries in terms of the division of historical responsibilities, the allocation of development space, the timing of countermeasures, and the choice of specific emission reduction methods. Therefore, both cooperation and conflict have occurred (Zhuang and Chen 2001). 


\section{Environmental diplomacy.}

As the world's second-largest economy and largest producer of carbon emissions, China's response to the "carbon peak" and "carbon neutral" commitment statement on global climate governance showed its constructive positive role and active global environmental responsibility. Thus, China actively leads global climate governance actions with its awareness of its responsibility to the world as the country with the largest carbon emissions (Xi 2020). China's environmental diplomacy will play an important role in achieving energy and environmental security, building a harmonious society, and establishing a positive international image. The impact of climate change on China's national security is widespread and will continue to increase. China should not only incorporate the response to climate change into its national socioeconomic development plans, but also include it in the overall national security framework (Zhang 2015). China should also embrace its key role in global economic growth and in responding to climate change with the goal of building a global ecological civilization guided by the idea of building a community with a shared future, through playing an active role as a responsible major player in global climate governance and coordinating climate governance actions at the global, national, and regional levels, actively building a global, national, and regional community to promote climate awareness for humanity, and striving to achieve positive interactions among all countries ( $\mathrm{Li} 2020$ ).

In the 5 years since the 2015 Paris Agreement, numerous historical differences and contradictions have resurfaced and the global political divide in relation to climate change has been altered by revisions to the discourse system, with disputes over climate-related issues among governments, businesses, and other actors, as well as differences among countries regarding carbon emissions and wealth levels affecting the division of responsibilities and contributions. The 2019 UN Climate Change Conference held in Madrid in December revealed the continuation of a significant North-South divide in terms of specific aspects such as emissions reduction and finance. This provides a glimpse into the future of global climate politics, with the growing disconnect between the slow UN process and the global community's dynamic needs. Countries are likely to continue to adjust their policies, which will inevitably reflect a lack of confidence in the effectiveness of the global climate governance mechanism and deep skepticism regarding the prospect of global decarbonization.

Overall, it appears that the 30-year-long process of global climate politics, and in particular global climate-related negotiations, while lacking in merit, offers some cautious hope. A better option for addressing climate change might have involved political leaders using an assessment and verification mechanism to send signals urging climate-action laggards to raise their levels of climate-related political engagement and climate governance. However, periodic reviews under the Paris Agreement framework have revealed a gap between countries' emissions-reduction commitments and their actions, leading to a vicious cycle of unmet emissions-reduction ambitions and reduced political trust among countries (Zhao 2021). Climate change risks may be intertwined with other nontraditional security issues, such as the COVID-19 pandemic, which trigger a chain of more uncertain negative effects. Therefore, it is necessary for all countries to act decisively. The problems presented by climate change cannot be solved by the UN alone. Action is required at many levels over a wide range of areas, including both national and international organizations, and the wider society, if the world is to successfully address the interrelated crises of climate change and the COVID-19 pandemic, and begin the process of economic recovery.

\section{Review of climate change research in sociology journals and prospects.}

The field of sociology cannot afford to remain distant from the issue of climate change, not only because climate change and its solutions involve a wide range of human behaviors and complex social mechanisms to which sociology should be able to contribute, but also because climate change is altering the object of sociological research, namely, human society. Sociologists will be unable to improve their understanding of contemporary society if they do not include climate change in their research scope.

Sociology intuitively reveals the unevenness of societal perceptions and actions regarding climate change, and explains the reasons for this unevenness by drawing on its familiar theories of power, interests, and values, as well as its analysis of social structures, social processes, and social practices. By analyzing human beings and the complex processes of human society, sociology reveals the complexity and diversity of the socioeconomic and cultural impacts of climate change, especially the differential distribution of these impacts and their consequences in terms of social injustice and social conflict. The complexity of addressing climate change makes it imperative for sociologists to remain reflective, critical, and constructive regarding both their research subjects and their own biases. Social development often brings unanticipated consequences and only by remaining reflective and critical can we constantly revise our knowledge of how society operates and develops, uncover the reasons for unexplained findings and practice preconceptions, and enrich the selectivity of social action. Figure 5 shows that 11 social science journals in the CSSCI source journals contained only 28 articles related to climate change or global warming, which was the lowest among the four essential social sciences. Most of these articles were 
related to demographic research exploring the relationship between climate change and population change. Population change, economic development, and energy technology are all influential factors on climate change (Jiang 2010). In addition, some studies have found that climate change has had an impact on mortality rates. The population mortality-air temperature curve is U-shaped and lower on the left and higher on the right. Population mortality is lowest in the $5-10{ }^{\circ} \mathrm{C}$ temperature range, while in higher temperatures, bacteria and other diseases are more likely to damage the human immune system, which leads to increased mortality (Li and Tian 2013).

Our review of the literature on climate change in various social sciences revealed that the effects of climate change have worsened social determinants such as poverty, education levels, and food security. It can also undermine efforts to achieve the UN's Sustainable Development Goals and exacerbate conditions that lead to health inequities and other inequalities among vulnerable groups. Climate change has also triggered events such as migration, which has led to large numbers of displaced people and conflicts that adversely affect people's health. Climate change affects human health by altering the external conditions of people's existence and thus population growth and mortality. However, much remains unknown about the impact of climate change on human health, such as the mechanisms by which climate change affects population mortality, health alerts, and the burden of disease. China's current laws and regulations related to climate change are basically focused on reducing greenhouse gas emissions, and the lack of attention to the effects of climate change on public health indicate that additional research is required prior to developing an appropriate climate change policy in the field of public health in China (Li and Tian 2013). China has considered social equity in developing its climate change mitigation actions by allocating more responsibility for mitigation to its wealthier regions. During the period covered by the 13th Five-Year Plan, China demanded that the wealthiest eastern provinces such as Beijing, Shanghai, and Tianjin reduce their energy intensity by $17 \%$, while some poorer western provinces such as Tibet, Qinghai, and Xinjiang are only required to reduce their energy intensity by $10 \%$ (Mi et al. 2020). Although the Chinese government is taking active measures to address climate change, its public expectations regarding the severity of the future effects of climate change are relatively low compared with other countries. In addition, it has been shown that factors such as income, marital status, age, and fertility all influence the public's acceptance of the government's climate change policies (Ge 2021). A future-oriented society will be more willing than a presentoriented society to accept the costs of addressing climate change in exchange for the long-term benefits of mitigation. Increasing individual willingness to take action in response to climate change and support for related policies may have a positive impact on the short-term effects of climate change. Public perceptions of the effects of climate change have a pronounced effect on people's attitudes toward government measures. If public acceptance must be increased, public awareness of the impact of climate change should also be increased. Hence, the social sciences must consider the society's approach to climate change when conducting climate change-related research in the future. Researchers must also promote climate change-related publicity, education, and training to increase the public's environmental awareness.

Our analysis shows that sociologists have given insufficient attention to climate change and global warming. In addition, there is a significant lack of research on climate change in the social sciences, which prevents a deeper understanding of the impacts of climate change and the most effective responses. In the future, social scientists should give greater attention to research on climate change-related issues. If we accept that climate change is caused by human activity and that human society must take action to address climate change, then we must consider the social complexity of climate change, that is, to the complex interplay among social agents, social dynamics, and social processes that both cause climate change and must respond to climate change. The impact of climate change has social properties and manifests itself as a social phenomenon that requires in-depth study by social scientists, in particular sociologists. Because of the complexity of the mechanism underlying the impact of climate change on human society, it is difficult for models to include all of the relevant variables. Sociology relies heavily on data collected from experiments or surveys, which may be either incomplete or nonexistent in relation to some variables and/or prone to measurement or other errors (Benjamin et al. 2018). Therefore, the models used in sociological analyses should be improved further and the data obtained should be reviewed and screened to enhance the accuracy and reliability of the analyses and provide practical solutions to the sociological problems caused by climate change. Sociology should better contribute to climate governance by providing a richer variety of alternative responses to climate change, developing more detailed assessments of the impact of climate change, and enabling the continuous improvement of climate governance institutions, structures, policies, mechanisms, and practices.

\section{Conclusion}

Our analysis showed that the annual number of articles published on climate change or global warming was only $27.57 \%$ of that published on pollution in journals related to the four essential social sciences of economics, management, politics, and sociology. This reflects the relative awareness 
of the issues of climate change or global warming. Furthermore, analysis of the CSSCI periodicals directory for the four essential social sciences revealed that as of September 1, 2020, 1179 articles had been published on climate change or global warming, or $26.81 \%$ of the number published on pollution. Thus, insufficient attention has been given to the issue of climate change or global warming. In addition, the four essential social sciences accounted for only $2.37 \%$ of all articles published on climate change or global warming, and thus more attention should be given to the impacts of climate change or global warming from social science perspectives.

The impact of climate change is a great challenge facing humanity today. Its complex causes and widespread effects mean that it is not confined to the natural science fields, but rather is a multidisciplinary problem. The four essential social sciences each have different perspectives on climate change. Economics is focused on how to improve the existing economic model to reduce carbon emissions, management is focused on how to reduce carbon emissions scientifically and rationally, political science is focused on the global response to the impacts of climate change, and sociology is focused on the relationship between climate change and human society and the overall ecosystem.

Based on our analysis of the literature on climate change in the four essential social sciences, we present the following recommendations for improving the climate change literature. First, there is a need to increase the consensus among Chinese social scientists on the importance and urgency of research on climate change-related issues by providing research guidance through competitive project application processes such as the National Natural Science Foundation of China and the National Social Science Foundation of China. Second, the policy whereby many Chinese universities have now established research institutes in schools of economics and management specializing in climate change-related issues such as carbon neutrality should be commended and other universities should be encouraged to follow suit.

Acknowledgements Chang Liu, PhD student of Tokyo Medical and Dental University, is gratefully acknowledged for her assistance in creating images for the manuscript.

Author contribution Conceptualization: Fanglei Zhong, Aijun Guo, and Xiaoyu Song; Methodology: Fanglei Zhong and Wenru Cheng; Formal analysis and investigation: Fanglei Zhong and Wenru Cheng; Writing — original draft preparation: Fanglei Zhong and Wenru Cheng; Writing — review and editing: Fanglei Zhong, Wenru Cheng, Qingping Cheng, and Asmat Ullah; Visualization: Fanglei Zhong and Wenru Cheng; Funding acquisition: Fanglei Zhong and Aijun Guo; Resources: Fanglei Zhong, Qingping Cheng, and Yuan Song; Supervision: Fanglei Zhong, Aijun Guo, and Xiaoyu Song.

Funding This research was funded by the National Key R\&D Program of China, grant number 2018YFD1100102, 2018YFC1509007; the National Natural Science Foundation of China, grant number
41801208; and the Fundamental Research Funds for the Central Universities, grant number 2019jbkyjd013.

Data availability Not applicable.

\section{Declarations}

Ethics approval and consent to participate Not applicable.

Consent for publication Not applicable.

Conflict of interest The authors declare no competing interests.

\section{References}

Benjamin K, Sovacool J, Steve S (2018) Promoting novelty, rigor, and style in energy social science: towards codes of practice for appropriate methods and research design. Energy Res Soc Sci 45. https://doi.org/10.1016/j.erss.2018.07.007

Cao JX, Yao B (2014) Carbon abatement and financial stability: analysis from the perspective of bank loans. China Industrial Economics 09:97-108, CNKI:SUN:GGYY.0.2014-09-009

Chen SY, Lin BQ (2019) The summary of the 1st forum for china's energy, environment and climate change economics. Econ Res J 54:203-208

Chen Y, Chen C, Liu Z, Hu Z, Wang X (2015) The methodology function of Cite Space mapping knowledge domains. Stud Sci Sci 33:242-253. https://doi.org/10.16192/j.cnki.1003-2053.2015.02. 009

Chu M, Xu SQ (2012) Exploration, practice and re-innovation of Green Patent System. Sci Technol Prog Policy 29:95-97. https://doi.org/ 10.6049/kjjbydc.2012010118

Deschenes O (2010) Climate Policy and Labor Markets. NBER Working Papers, No.16111. https://www.nber.org/papers/w16111

Ge J, Lin BQ (2021) Impact of public support and government's policy on climate change in China. Journal of Environmental Management 294. https://doi.org/10.1016/j.jenvman.2021.112983

Goodall AH (2008) Why have the leading journals in management (and other social sciences) failed to respond to climate change? J Manag Inq 17:4. https://doi.org/10.1177/1056492607311930

Harry C (2015) Climate economics: economic analysis of climate change and climate policy, edited by Richard S. J. Tol. Published by Edward Elgar, Cheltenham, UK, 2014, pp. 208 pages, ISBN: 178254591 3. Aust J Agric Resour Econ 59(2)

He JK, Teng F, Qi Y (2014) Research tasks and directions of new climate economics. China Popul Resour Environ 24:1-8. https:// doi.org/10.3969/j.issn.1002-2104.2014.08.001

He Y, Tang QL, Wang KT (2014) Carbon disclosure, carbon performance, and cost of capital. Accounting Research 01, 79-86 + 95 . https://doi.org/10.3969/j.issn.1003-2886.2014.01.012

Hu JB, Ren YY, Ding ZG (2015) Carbon barriers in international trade and countermeasures under climate change. Inquiry Into Economic Issues 10:137-141, CNKI:SUN:JJWS.0.2015-10-021

IEA (2020) Global CO2 Emissions in 2019. https://www.iea.org/artic les/global-co2-emissions-in-2019. 2020-02-11

IPCC (2013) Climate Change 2013: the Physical Science Basis. Contribution of Working Group I to the Fifth Assessment Report of the Intergovernmental Panel on Climate Change. Cambridge University Press 
Jiang LW (2010) The impacts of demographic dynamics on climate change. Population Research 34(01):59-69. CNKI:SUN:RKYZ.0.2010-01-006

Jin LQ, Liu R (2009) Low-carbon economy and the transformation of China's economic development model. Inq Econ Issues 1:84-87. https://doi.org/10.3969/j.issn.1006-2912.2009.01.015

Li HM (2020) The "action turn" of global climate governance and China's strategic option. International Review 03:57-85. CNKI:SUN:GJGC.0.2020-03-004

Li SS, Tian YX (2013) The effect of the regional climate change on the death rate in China: Based on the panel data analysis. Popul Econ 3:20-25. https://doi.org/10.3969/j.issn.1000-4149.2013.03.003

Lin L (2012) A study of international carbon financial market development and risks in the context of low-carbon economy. Contemporary Finance \& Economics 02:51-58. CNKI:SUN:DDCJ.0.2012-02-012

Lin GH, Lu YY (2019) The impact of climate change on agricultural total factor productivity and its countermeasures. Rural Economy 06:114-120. CNKI:SUN:NCJJ.0.2019-06-016

Liu FG (2007) Research on the classification of Chinese journals by university scientific research management departments. China Association of Higher Education (05):60-62. https://doi.org/10. 16298/j.cnki.1004-3667.2007.05.022

Luo LW, Ru X, Zhao F (2018) Advances in research on the economic impacts of climate change. Econ Perspect 10:116-130. CNKI:SUN:JJXD.0.2018-10-011

Luo YB, Liang GH (2012) Feasibility analysis of issuing low carbon lottery in China. Management World 12:173-174. https://doi.org/ 10.19744/j.cnki.11-1235/f.2012.12.017

Ma X, Li JF, Zhang YX (2009) A non-negligible issue before Copenhagen - climate change research and the BAU scenario in international negotiations. Int Econ Rev 06:5-8. CNKI:SUN:GJPP.0.2009-06-004

Michael LG, Zhang MH (2011) The current status of climate change research. Nat Clim Chang 12 . https://doi.org/10.1038/nclimate10 93

Mi ZF, Mi JL, Zheng J, Meng JM et al (2020) Economic development and converging household carbon footprints in China. Nature Sustainability 3(7). https://doi.org/10.1038/s41893-020-0504-y

[Practice new theory] Promote economic and social development of comprehensive green low-carbon transformation. https://share. gmw.cn/theory/2020-11/27/content_34407789.htm, 2020-11-27.

Qiao XN, He ZL (2016) Understanding the Paris agreement: a double-layered analysis framework of industry transition and carbon emissions. China Review of Political Economy 7:118-143. CNKI:SUN:ZZJP.0.2016-03-010

Seraina B, Gunter S (2010) To mitigate or to adapt: how to confront global climate change. Eur J Polit Econ 27(1). https://doi.org/10. 1016/j.ejpoleco.2010.05.001

Stephan, S.; Hannes, W. Interdisciplinary energy research and energy consumption: what, why, and how?. Energy Research \& Social Science 2015, 10, https://doi.org/10.1016/j.erss.2015.08.001

Wang F, Wu LH, Yang C (2010) Driving factors for growth of carbon dioxide emissions during economic development in China. Economic Research Journal 45:123-136. CNKI:SUN:JJYJ.0.2010-02-011

Wei YM, Yuan XC, Wu G, Yang L (2014) Climate change risk assessment: a bibliometric analysis based on web of science. Bull Natl Nat Sci Found China 5:347-356. https://doi.org/10.16262/j.cnki. 1000-8217.2014.05.001

Weitzman ML (2011) Fat-tailed uncertainty in the economics of catastrophic climate change. Rev Environ Econ Policy 5(2):275-292. https://doi.org/10.1093/reep/rer006

$\mathrm{Xi}$ addresses the general debate at the seventy-five UN General Assembly. http://cpc.people.com.cn/GB/n1/2020/0923/c64094-31871 240.html. 2020-09-23

Xu SL (2001) Pluck a dime and benefit the world, not for also- the United States to withdraw from the Kyoto Protocol analysis. Intertrade 6:32-34. https://doi.org/10.3969/j.issn.1002-4999.2001.06. 007

Yang HL (2010) Carbon trades, national welfare and carbon market construction of China. China Soft Science S2:55-61, CNKI:SUN:ZGRK.0.2010-S2-012

Yang JG (2010) The industrial revolution with low-carbon economy as the core is coming. Economic Vision 04:33-34. CNKI:SUN:JLJH.0.2010-04-016

Ye MX (2013) Study on the challenges and paths of low-carbon transformation in cities. Asia-pacific Economic Review 05:132-135. https://doi.org/10.16407/j.cnki.1000-6052.2013.05.001

Yifu L (2019) China should respond to global climate change with a developmental perspective. Resource Recycling 10:57-59

Zhang HB (2015) The impact of climate change on China's national security: a perspective of the overall national security outlook. The Journal of International Studies 36:11-36 + 5. CNKI:SUN:GJZY.0.2015-04-002

Zhao B (2021) The complex predicament of global climate change. Contemporary International Relations (04):37-43+27

Zhu SL, Zhu L, Zhao XF, Wang WT, Zhang WX (2020) A review of China's climate policies and actions since the launch of the 12th Five Year Plan. China Popul Resour Environ 30:1-8. https://doi. org/10.12062/cpre.20200332

Zhuang GY, Bo F, Zhang J (2018) China's role and strategic choice in global climate governance. World Economics and Politics 04:4-27 + 155-156. CNKI:SUN:SJJZ.0.2018-04-002

Zhuang GY, Chen Y (2001) An analysis of country groupings and their impacts in international climate negotiations. Pacific J 2:72-78. https://doi.org/10.3969/j.issn.1004-8049.2001.02.010

Zou LL, Chen PP, Wu Y, Wang Y (2019) Research on the cooperative characteristics and evolution of subjects in China's innovation of clean technology. Studies in Science of Science 37:1702-1711. CNKI:SUN:KXYJ.0.2019-09-019

Publisher's note Springer Nature remains neutral with regard to jurisdictional claims in published maps and institutional affiliations. 